\title{
Promoting Growth and Innovation through Acquisition: A Choice Modeling Approach
}

\author{
$\mathrm{Yu} \mathrm{Yu}^{*}$ \\ Vithala R. Rao*
}

March, 2009

*Y u Yu is a Marketing D octoral Candidate at the Johnson G raduate School of Management, 401 Sage Hall, Cornell University, Ithaca, NY, 14853. Phone: 862-596-1551, E-mail: yy235@ cornell.edu. Vithala Rao is the Deane W. Malott Professor of Management and Professor of Marketing and Quantitative Methods at the Johnson G raduate School of Management,, 351 Sage Hall, Cornell University, Ithaca, NY 14853. Phone: 607-255-3987, E-mail: vrr2@,cornell.edu.

The authors are grateful to Samuel Henkel for his assistance in data collection for this paper. They also acknowledge helpful comments from Kenneth Train, Vrinda Kadiyali and Sean Nicholson. 


\title{
Promoting Growth and Innovation through Acquisition: A Choice Modeling Approach
}

\begin{abstract}
While innovation and growth can be promoted internally through focus on research and development (R\&D), many firms find acquisition from external sources to be a fast and attractive alternative. Despite the numerous theories of merger and acquisition in the literature, no empirical study has tackled the problem of target selection in an acquisition. This paper is the first to study the target selection criteria in an empirical setting. It quantifies the elusive concept of synergy by developing novel measures of similarity and complementarily between the acquirer and the target that are more comprehensive than the existing measures in the literature. Using an innovative application of the discrete choice model, the authors find that firms use acquisition to promote growth and innovation in areas of strategic interest. Specifically, acquirers choose targets whose product markets match their own $R \& D$ projects, and targets whose $R \& D$ projects match their own product markets. These findings provide support for the knowledge based view of the firm and lay the foundation for future research in this area.
\end{abstract}

Keywords: Acquisition, Choice Modeling, Synergy, Growth, Innovation and Pharmaceuticals 
"The fundamental impulse that sets and keeps capitalist engine in motion comes from the new consumers' goods, the new methods of prodution, the new markets, the new forms of industrial organization, ..., that incessantly revolutionizes the economic structure from within, incessantly destroying the old one, incessantly creating a new one." (Schumpeter 1942, p83).

Because of their essential roles in a firm's success, innovation and growth have long been research priorities in the marketing discipline (2008 and 2010 MSI research priority). While internal $\mathrm{R} \& \mathrm{D}$ can help promote innovation and growth, the process of building a healthy market share and R\&D pipeline takes considerate amount of time. A fast and attractive alternative for firms facing intense competition in the marketplace and strong pressure from the stock market is to acquire another firm with existing products and R\&D projects. Probably because of these reasons, the number of acquisitions (used interchangeably with mergers, M\&A) involving US firms is quite high; it peaked in 2006 at 12,000 deals with the total value exceeding 1.4 trillion dollars.

Due to such large amount of acquisition activity and because of its impact across all organizational functions, acquisitions have been studied in many disciplines (such as economics, strategy, finance, marketing etc). While numerous theories have been proposed on why firms undertake acquisitions, the empirical literature tests these theories using acquisition outcomes rather than test acquisition motives directly. However, the findings on acquisition outcomes have been mixed $^{1}$, and many acquisition reasons may lead to the same acquisition outcome. Therefore, it is difficult to establish a clear link between acquisition outcomes and motives. Moreover, these studies ignore the integration process in an acquisition (Jemison and Sitkin 1986) which can drive a wedge between the outcome of an acquisition and its motive. For instance, a failed 
acquisition doesn't necessarily imply agency motives such as empire building or risk reduction incentives (Amihud and Lev 1981) because unsuccessful integration may have caused the failure.

Against this background, this paper directly tests the theoretical reasons for acquisitions without relying on acquisition outcomes and without being tainted by the integration process. The focus is on the empirical target selection criteria, especially the strategic criteria used by acquirers to choose targets.

Why do two firms want to become one? Synergy has often been cited as one of the prime reasons underlying acquisition decisions (Walter and Barney, 1990). Synergy is said to exist when the combined return on a company's resources is greater than the sum of its parts. It can arise from many sources, such as economies of scale in operations, increased market power, assimilation of technical or tacit knowledge, favorable financial market treatment of larger firms, diversification of risks, etc (Salter and Weinhold 1979).

Although frequently used in the theoretical literature, synergy remains an elusive concept that has defied accurate measurement. In the empirical literature, synergy is often measured by relatedness or similarity (rather than complementarity) in the product markets (rather than $R \& D$ projects). The few studies that measure R\&D synergy rely on the number and citation of patents (Prabhu, Chandy and Ellis 2005) or R\&D spending (Swaminathan, Murshed and Hulland, 2008). However, R\&D spending measures the input not the output of innovation whereas patents are a rough measure for innovation since patent applications represent very early stage of $R \& D$. We quantify the concept of synergy in a holistic manner by developing novel measures of similarity and complementarity between the acquirer and the potential target in product markets and in $R \& D$ projects, with the latter weighed by their probability of conversion to final products. Besides developing the most comprehensive measures of market and knowledge synergies so far, 
we also capture the interaction between these two which has not been measured in the literature (see Table 1 and the web appendix A for a comparison of our measures with those in the literature).

--Insert Table 1 here-

Through our measures of operational synergy, we test several hypotheses on acquisition motives suggested by the strategy theory and the knowledge based view of firms. We use product market synergy measures to test market power, as well as economies of scale and scope from production and marketing. We use R\&D synergy measures to test knowledge specialization and knowledge spillover effects. Finally, we use synergy measures capturing the interaction between product markets and $R \& D$ projects to test the strategic direction of acquirer in terms of balancing short term revenue growth and long term innovation potential.

The empirical setting of this paper is in the pharmaceutical industry. Due to the significant amount of acquisition activity and the essential role innovation plays in this industry, it is an ideal testing ground for our topic. This industry has been studied in several other marketing papers on acquisition and innovation. Swaminathan, Murshed and Hulland (2008) discuss how strategic alignment affects the outcome of acquisitions. Homburg and Bucerius (2005) study the impact of integration on the outcome of acquisitions. Sorescu, Chandy and Prabhu (2007) claim that the acquirer's product capital affects the success of an acquisition. Prabhu, Chandy and Ellis (2005) find a positive effect of acquisition on innovation. These studies take acquisition deals as given and study their impact on growth and innovation. In contrast, we study the target selection decision and its link to acquirer's incentive such as achieving growth and innovation synergies.

Using an innovative application of the discrete choice model, we find that firms in the pharmaceutical industry use acquisition to promote growth and innovation in areas of strategic 
interest. Instead of seeking targets whose R\&D portfolio matches their own, acquirers choose targets whose products match their R\&D projects, thus leapfrogging from research knowledge to immediate market growth in strategic areas where the acquirer desires to establish its presence and exploit the acquired knowledge to improve its R\&D projects. Moreover, instead of acquiring targets with similar product portfolios, acquirers focus on targets whose R\&D projects match their products, thus building an innovation pipeline in strategic areas with aging products that can be transformed using its experience and resources into marketable products in the future.

These findings provide support for knowledge-based theories of the firm which argue that acquisitions are driven by the desire to acquire tacit knowledge and potential for innovation that are otherwise locked within the boundaries of firms. An ideal target should fit with acquirer's existing knowledge so that the acquired knowledge can be fully utilized, and it should bring in new knowledge to expand the acquirer's reach in future directions, thus promoting growth and innovation in areas of strategic interest.

This paper makes several contributions to the literature. First, this paper pioneers the empirical study of target selection in acquisitions. The extant empirical literature has either studied the outcome of acquisitions (see Trautwein 1990 for a review) or the conditions under which firms tend to initiate mergers (Higgins and Rodriguez 2006, Danzon, Epstein and Nicholson 2007). The choice of target in an acquisition and its link with the acquirer's incentives has been ignored by the empirical literature. To fill this gap, several simulation studies and survey-based researches have explored target choice (Silhan and Thomas 1986, Kroll and Caples 1987, Schniederjans and Fowler 1989, Rao, Mahanjan and Varaiya 1991), but these approaches lack much needed realism. The empirical target choice studied in this paper serves as a missing link between the theoretical reasons for acquisition and the management decisions in reality. 
Second, this paper explicitly models the elusive concept of synergy, thus allowing more accurate and refined testing of the theories on mergers and acquisitions. Using our novel measures of synergy which are more comprehensive than the existing measures, we are able to obtain a precise picture of the potential fit between acquirer and target in terms of their products and R\&D. These synergy measures help reveal how firms in a knowledge intensive industry use acquisition to achieve immediate growth and long-term innovation potential, complementing the findings of marketing literature on the positive effect of acquisition on growth and innovation.

Third, this paper provides a novel application of the discrete choice model beyond its conventional scope in marketing. The primary application of this model in marketing has been to study brand choice by individuals or households in a Business to Consumer setting. This paper provides a new application of the choice model in Business to Business decision settings. By incorporating the potential synergies from a deal in the decision maker's utility, our model can be adapted to other business settings where mutual gains and strategic fit are important.

\section{THEORY AND HYPOTHESES}

While many theories have been proposed across academic disciplines ${ }^{2}$ to explain acquisitions, we will focus on the strategy theory and the knowledge based view of firm. For a comprehensive review of various acquisition theories, refer to Parvinen (2003).

In the strategy theory, three sources of synergies have been identified related to mergers and acquisitions. These are technical economies, pecuniary economies, and diversification economies (Lubatkin, 1983). Technical economies are scale economies that occur when the physicial process inside a firm is altered so that the same amounts of inputs, or factors of production, produce a higher quantity of outputs. The two main types of techincal economies are marketing and production economies (Shepherd 1979). These economies can occur in several 
situations such as: when the products of two or more businesses use common distribution channels; where there is an opportunity for tie-in sales that can increase the productivity of the sales force; where opportunities for common advertising and sales promotion exist; where common production facilities can be utilized and the overhead spread over larger volume; when there is R\&D carryover from one product to another, and so on (Salter and Weinhold 1979).

Pecuniary economies are achieved by the firm's ability to dictate prices by exerting market power achieved primarily through larger size. The two types of pecuniary economies are monopoly and monopsony economies. The former comes from the ability of a firm to force buyers to accept higher prices. The later comes from the firm's ability to force suppliers to accept lower prices (Porter 1980).

Diversification economies are achieved by improving a firm's performance relative to its risk attributes or by lowering its risk attributes relative to its performance (Lubatkin 1983). Diversifying acquisitions have been shown to bring less gain for acquirers than non-diversifying ones (Singh and Montgomery 1987), and are more prone to agency problems. In order to avoid the confounding effect of agency issues, we study deals wherein both acquirer and target are in the same industry, thus ruling out diversification economies as the source of synergy in this study.

The knowledge based view of firm provides a theoretical justification for acquisition based on knowledge and learning. According to this school: firms exist because they produce and utilize knowledge, particularly tacit knowledge, more efficiently than markets (Kogut and Zander 1992); firms' internal organization is a shared context to integrate and utilize essentially local knowledge in order to build and leverage core competencies (Foss and Foss 2000); M\&A is the amalgamation of two sets of knowledge resources in order to attain a resource combination, 
which would not have been attainable otherwise. Such a situation occurs most often in the presence of possibilities for promoting learning and innovation (Parvinen 2003).

The knowledge-based theory has been used by many researchers as the foundation for R\&D motivated acquisition (Prabhu, Chandy, Ellis 2005). A distinctive stream of literature has concentrated on the transfer and acquisition of unique technologies through M\&A (Hagedoorn and Sadowski 1999). Organizational learning through M\&A (e.g. Haleblian and Finkelstein 1999) and M\&A for technological and organizational innovation (e.g. Kabiraj and Mukherjee 2000) are related explanations. The main idea behind these explanations is that acquisition provides access to target's tacit knowledge which is difficult to imitate but is a critical source of innovation.

There are areas of overlap between the strategy theory and the knowledge based theory. For example, the acquisition of products can be explained by the strategy school as production economies of scale and by the knowledge-based theory as the desire to learn the production knowledge embedded in the target product. Similarly, the acquisition of R\&D projects can be motivated by the strategy school as scale economy in R\&D, and by the knowledge-based theory as the only way to obtain target's proprietary technology and tacit knowledge. We now develop more refined hypotheses on acquisition incentives using these two theories.

\section{Market Intensification}

An acquirer may want to choose a target that has similar products as itself. On the supply side, efficiency can increase when resources are shared for the production and distribution of larger quantity of similar products. Such scale economies can occur in specific functional areas, such as manufacturing, R\&D, and selling and distribution (Salter and Weinhold, 1979; Rumelt, 1974), as well in the more general areas such as administration and financial management. The 
scale economy can also be explained by transaction cost economics since the larger scale lowers the transaction costs of using a factor of production (Richter 1999).

On the demand side, acquisition of similar products may increase the market power of the combined company. A market participant is said to have market power when it has the ability to influence price, quantity, and the nature of the product in the market place (Shepherd, 1970:3). Market power, in turn, may lead to excess returns. A firm's market power may be increased through horizontal acquisitions or through market extension acquisitions since its effective size is increased relative to its competitors. These arguments lead to our first hypothesis:

H1: In an acquisition, the acquirer seeks a target whose product portfolio intensifies its own.

Empirical research by Ajuha and Katila (2001) suggests that too much business overlap causes redundancy and reduces learning from each other, whereas too little overlap causes difficulty in integration. Therefore the relationship between similarity and synergy may resemble a bell curve: synergy increases first as companies are far apart from each other, but starts decreasing after a certain point. We will test for such non-linearity as a robustness check.

\section{Market Expansion}

Many firms regard acquisition as a quick way to expand into new markets, obtain new distribution channels, and acquire new production techniques. Referred to as economy of scope, synergy arising from such situations can come from utilization of the same set of resources, such as production facilities, distribution channels, and management personnel (Salter and Weinhold, 1979; Rumelt, 1974). The difference between economy of scale and economy of scope lies in the degree of resource sharing. Scale economies arise when capacity utilization is increased through more production of a single (type of) product, and scope economies arise when capacity utilization is increased though the shared production of two or more (different types of) products 
(Singh and Montgomery 1987). For example, two antibiotic drugs can share common production facilities and sales force, whereas a cancer drug and a common cold drug may only benefit from managerial sharing and financial economies. These arguments lead to our second hypothesis:

H2: In an acquisition, the acquirer seeks a target with product markets that the acquirer lacks.

\section{$R \& D$ Intensification}

An acquirer interested in pipeline replenishment may want to choose targets that have similar R\&D projects as itself. As in the case of product markets, economy of scale in R\&D can also generate potential efficiency gains through sharing of $R \& D$ facilities, and collaboration of research scientists. Moreover, acquisition of similar R\&D can be motivated using knowledge specialization. Knowledge is created by individual human beings, and to be efficient in knowledge creation and storage, individuals need to specialize (Simon, 1991). With a larger scale of R\&D, research personnel can specialize and develop depth of knowledge. Developing depth of knowledge in key fields enables firms to gain competency and produce new knowledge in those fields, and thus innovate (Hamel and Prahalad 1994). Expertise in a field also enables an acquiring firm to judge whether a target firm technology is genuinely valuable, thus helping pick better targets (Cohen and Levinthal 1990). Moreover, the similarity of knowledge between the acquirer and the target is crucial to the acquirer's ability to absorb the target's knowledge and use it for innovation (Cohen and Levinthal 1990). Therefore, we propose the following hypothesis:

H3: In an acquisition, the acquirer seeks a target with pipeline projects that strengthen the acquirer's existing $R \& D$ portfolio.

However, in the case of highly similar R\&D acquisitions, there will be less new knowledge to absorb. Too much relatedness may result in overlapping and redundant research (Rindfleisch and Moorman 2001) and fewer opportunities to combine different types of knowledge in creative 
ways. Therefore Prabhu, Chandy and Ellis (2005) suggest a nonlinear relationship between knowledge similarity and innovation. We will address this issue in the robustness section.

\section{$R \& D$ Expansion}

Although specialization can improve efficiency, with changes in market preferences and technological opportunities, knowledge that was once a source of competitive advantage may become irrelevant (Volberda 1996). To avoid being locked out of emerging technical domains, firms need a broad base of knowledge (Leonard-Barton 1995). Although some researchers find that greater breadth can cause a firm to spread resources too thinly (Wernerfelt and Montgomery 1988), most of the research suggests that breadth in knowledge is helpful for innovation (Cohen and Levinthal 1990; Henderson and Cockburn 1994). The broader a firm's existing knowledge, the greater is its ability to combine knowledge in related fields in a more complex and creative manner (Kogut and Zander 1992), and the knowledge spillover may result in unexpected discoveries (Prabhu, Chandy and Ellis 2005). Therefore, the acquirer may want to achieve breadth of knowledge through acquisitions, which is the gist of the following hypothesis:

H4: In an acquisition, the acquirer seeks a target with pipeline projects extending beyond the acquirer's existing $R \& D$ project portfolio.

\section{Market to R\&D Intensification}

The knowledge based theory provides us a new lens to looks at all activities in a firm as knowledge. As Kogut and Zander (1992) claim, firms exist because they produce and utilize knowledge, particularly tacit knowledge more efficiently than markets. From this perspective, the firms which successfully convert R\&D projects into marketable products and support those products with marketing, sales, and distribution channels possess important knowledge from these experiences. Such experiences can be very valuable for other firms that have incomplete 
R\&D project in similar areas. Successful implementation of these processes also requires upfront investment in production, marketing, distribution channels, which a small firm with a good R\&D project may not have. Therefore synergies can be created through the fusion of a firm with existing products and sufficient revenue, and a firm with $R \& D$ projects in similar areas that need prelaunch support. Such acquisitions can also help the acquirer build its long-term innovation potential in strategic areas with aging products that can be transformed into marketable products in the future. Therefore, we propose the following hypothesis.

H5: In an acquisition, the acquirer seeks a target with product pipeline in similar markets as its existing products.

\section{R\&D to Market Intensification}

Visionary CEOs set their eyes on the future when they choose which R\&D projects to develop. Therefore a company's pipeline should reflect its future direction. However, the progress of $R \& D$ projects is slow and not always on schedule. If the company is eager to enter a new market, but its internal $R \& D$ is not ready, acquiring existing products is a natural alternative. The expertise acquirer has gained from its existing R\&D projects can help it judge the potential of the target firm's products (Cohen and Levinthal 1990). From the knowledge based theory, synergies can arise in such a case if the acquirer can exploit the knowledge gained from the acquired products to improve its delayed R\&D project or create new knowledge. In short, an acquirer may seek immediate revenue growth by choosing a target whose products match its R\&D portfolio because of its desire to establish its presence in those markets and exploit the acquired knowledge to improve its R\&D projects. This leads to our final hypothesis:

H6: In an acquisition, the acquirer seeks a target that has existing products in similar areas as the acquirer's $R \& D$ projects. 


\section{MODEL AND METHOD}

\section{Model Specification}

We use the discrete choice model to study the firm's choice of acquisition target. This paper is one of the pioneers to apply the choice model to corporate decision making context and the first to apply it to study acquisition choice. Levine (2007) has applied the choice model to corporate decision making in the drug licensing market.

We introduce the random utility framework of choice model (McFadden 1973). Acquirer, labeled $j$, faces a choice among $K$ alternative targets. The acquirer $j$ chooses an alternative that provides the highest utility $U_{j k}>U_{j d}, \forall d \neq k, d, k \in(1, \ldots, K)$. The utility expression can be decomposed as $U_{j k}=V_{j k}+\varepsilon_{j k}$, where $\varepsilon_{j k}$ captures the factors that are observed by the acquirer but are not observed by the researchers. To obtain a close form solution, $\varepsilon_{j k}$ is assumed to follow i.i.d. extreme value distribution with mean 0 and variance $\pi^{2} / 6$. Under this assumption, the probability that acquirer $j$ chooses alternative $k$ is: $P_{j k}=\operatorname{Prob}\left(U_{j k}>U_{j d} \forall d \neq k\right)=e^{V_{j d}} /\left(\sum_{k} e^{V_{j k}}\right)$. Given that we utilize data over multiple years, we add the subscript for time. The model is estimated using maximum likelihood estimation with the log-likelihood expression:

$L L=\sum_{j=1}^{J} \sum_{t} \sum_{k} y_{j k t} \ln P_{j k t}$, where $y_{j k t}$ is an indicator variable representing the acquirer's choice.

We formulate the overall utility of acquirer firm $j$ from choosing alternative $k$ at time $t$ as:

$$
U_{j k t}=\underbrace{\sum_{l=1}^{L} \alpha_{l} x_{k, l, t}}_{1}+\underbrace{\sum_{m=1}^{M} \beta_{m} D_{k, m, t}}_{2}+\underbrace{\sum_{n=1}^{N} \kappa_{n} \phi_{j, k, n, t}}_{3}+\varepsilon_{j, k, t}
$$

- $X_{k, t}=\left(x_{k 1, t}, x_{k 2 t}, \ldots, x_{k L t}\right)$ denotes the vector of financial attributes of the alternative $k$ at time $t$.

- $D_{k, m, t}$ denotes control variables. We will discuss these variables in detail in following paragraphs. 
- $\phi_{j, k, n, t}$ denotes the synergy between the acquirer $j$ and alternative $k$ at time $t$. We measure this synergy using intensification and expansion factors as discussed in the following paragraphs. - $\varepsilon_{j, k, t}$ follows iid extreme value distribution

We do not include acquirer characteristics as stand-alone variables because in conditional logit model, any $j$ specific terms that are not interacted with target $k$ related-variables will drop out from the estimation and can not be identified. The variables $X_{k}, D_{k, m, t}$ and $\phi_{j, k, n, t}$ used in the estimation are provided in Table 2. These three components of the utility function are described below. --Insert Table 2 here-

Financial variables: The first component of the utility function comprises three variables selected out of 22 financial and accounting variables that measure the overall welfare of the target. We use factor analysis to assist in the variable selection process, the details of which are discussed in the data section. The three selected variables are Total Assets, Book Leverage, and Return on Assets. Total Assets measures the overall scale of the firm's business and is correlated with sales and R\&D expenditure. Book Leverage measures the proportion of the firm's book assets that are financed by book debt rather than book equity. If this ratio is too high, the company may face the risk of financial distress because of high interest expense and if this ratio is too low, the company is not fully utilizing the tax shield of debt. Return on Assets is a profitability measure calculated as the income generated by the firm as a proportion of its assets.

Control variables: We use several control variables based on the findings of previous research. An "alliance" dummy is included based on the findings of Higgins and Rodriguez (2006) that firms are more likely to acquire past or current alliance partners because they have more information about those firms through the alliance relationship. A "large firm" dummy is motivated by the finding of Danzon, Epstein and Nicholson (2007) that large acquisitions behave 
very differently from small ones. This is intuitive since acquiring a large firm is expensive and requires a lot more executive resources to plan the challenging integration processes after merger. We include "culture" variables suggested by Prabhu, Chandy and Ellis (2005), because cultural differences can affect the integration process. The culture here refers to organizational culture, market culture, and scientific culture of the acquirer and the potential target firms. We measure organizational culture with the ratio of acquirer's size and potential target's size (measured by sales); market culture with a dummy variable indicating the matching of Standard Industrial Classification (SIC) codes of acquirer and potential target; scientific culture with a dummy variable indicating whether the potential target is a biotechnology company.

Synergy variables: In this section, we provide a general framework for calculating potential synergies which can be readily adapted to other industries. The data section explains how the framework is used in this paper.

Assume that the set of all drugs $D=\left\{D_{1}, D_{2} \ldots, D_{I+J}\right\}$ comprising approved drugs $A=\left\{A_{1}, \ldots, A_{I}\right\}$ and pipeline drugs $P=\left\{P_{1}, \ldots, P_{J}\right\}$ with $D=A \cup P$ can be classified into therapy classes $C=\left\{C_{l}, \ldots C_{K}\right\}$ using some criteria such as the type of disease each drug treats. Let this classification be given by the mapping $f: D \rightarrow C$. Also, assume that the mapping $g: D \rightarrow R^{+}$assigns a positive real valued score to each drug in $D$, based on the market potential of that drug. The market potential of a drug could be measured by the sales revenue for an approved drug and the expected sales revenue for a pipeline drug. If sales figures are not available, market potential could be proxied by the clinical probability of FDA approval for a pipeline drug and the patent status for an approved drug.

Assume that $C$ can be partitioned into a tree with non-overlapping nests based on the proximity of therapy classes in $C$. Let this partition be represented by $C=C^{1} \supset C^{2} \supset \ldots \ldots \supset C^{N}$ 
subject to the conditions $C^{n}=\bigcup_{j \in C^{n} C^{n+1}} C_{j}^{n}$ and $C_{j}^{n} \bigcap C_{k}^{n}=\phi \forall j, k \in C^{n} \backslash C^{n+1}$ where $C_{j}^{n}=C_{j}^{n \backslash n+1} \bigcup\left(\bigcup_{\text {some } k \in C^{n+1} \backslash C^{n+2}} C_{k}^{n+1}\right)$ and $C_{j}^{n / n+1}=\left\{\exists ! j \in C^{n} \backslash C^{n+1}\right\}$. Here $n$ represents the level of tree (ranging from the highest level $l$ to lowest level $N$ ), $C^{n}$ is the set of all therapy classes that are at level $n$ or below, $C^{n} \backslash C^{n+1}$ is the set of all therapy classes at level $n$, and $C_{j}^{n}$ is the subtree originating from therapy class $j$ at level $n$. A proximity tree is illustrated in Figure 1 . The classification of therapy classes into various nests of a proximity tree could be done using a variable $d\left(C_{i}, C_{j}\right)$ which measures the subjective or objective distance between therapy classes $C_{i}$ and $C_{j}$. Such a tree could be formulated using a hierarchical clustering method (e.g. Anderberg, M.R. 1973, Sneath, P.H.A. and Sokal, R.R. 1973, Johnson, S.C. 1967). Hierrarchical clustering methods have been used extensively to study proximity data in several disiplines such as taxonomy, psychology, linguistics, etc (see Sattath, S. and Tversky A.1977 for examples).

--Insert Figure 1 here--

Assume that a firm $x$ has a portfolio of drugs $D^{x}=A^{x} \cup P^{x}$. The market score of firm $x$ for therapy class $C_{i}$ given by $s_{m}\left(C_{i}, x\right)=\sum_{A_{i} \in f^{-1}\left(C_{i}\right) \cap A^{x}} g\left(A_{i}\right)$ captures the market potential of approved drugs of firm $x$ in therapy class $C_{i}$. Likewise, the $R \& D$ score $s_{r}\left(C_{j}, x\right)=\sum_{P_{j} \in f^{-1}\left(C_{j}\right) \cap P^{x}} g\left(P_{j}\right)$ captures the market potential of all pipeline drugs of firm $x$ in therapy class $C_{j}$.

The market intensification factor $I_{m, m}(x, y)$ for acquirer $x$ and potential target firm $y$ measures the similarity of the two firms' approved drugs using the following expression

$$
I_{m, m}(x, y)=\sum_{C_{i} \in\left\{: z=f\left(A_{i}\right) \forall A_{i} \in A^{x}\right\}} \sum_{C_{j} \in\left\{: z:=f\left(A_{i}\right) \forall A_{i} \in A^{y}\right\}} h\left(d\left(C_{i}, C_{j}\right), s_{m}\left(C_{i}, x\right), s_{m}\left(C_{j}, y\right)\right)
$$

where $h: R^{3} \rightarrow R$ is subject to $\frac{\partial h_{m, m}(d, r, s)}{\partial d} \leq 0, \frac{\partial h_{m, m}(d, r, s)}{\partial r} \geq 0$ and $\frac{\left.\partial h_{m, m}(d, r, s)\right)}{\partial s} \geq 0$. Here, 
$h\left(d\left(C_{i}, C_{j}\right), s_{m}\left(C_{i}, x\right), s_{m}\left(C_{j}, y\right)\right.$ captures the similarity of the acquirer's approved drugs in therapy class $C_{i}$ and the target's approved drugs in therapy class $C_{j}$. This similarity factor decreases with the distance between $C_{i}$ and $C_{j}$ and increases with the market potential of acquirer's approved drugs in $C_{i}$ and the target's approved drugs in $C_{j}$. The market intensification factor is the sum of such similarity factors across all the acquirer and target therapy classes.

The $\boldsymbol{R} \boldsymbol{\&} \boldsymbol{D}$ intensification factor $I_{r, r}(x, y)$ is defined similar to the market intensification factor except that it uses R\&D scores to measure the similarity of the two firms' pipeline drugs



The market to $\boldsymbol{R} \& \boldsymbol{D}$ intensification factor $I_{m, r}(x, y)$ is defined similar to the above factors to measure the similarity of the acquirer's approved drugs with the target's pipeline drugs.

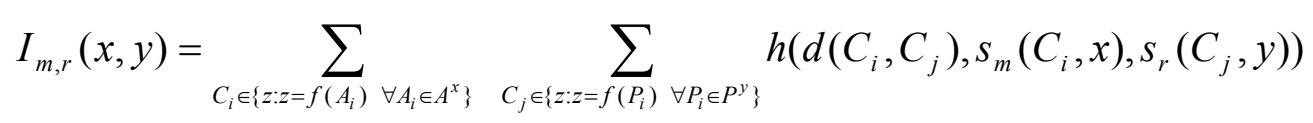

The $\boldsymbol{R} \& \boldsymbol{D}$ to market intensification factor $I_{r, m}(x, y)$ is defined similar to the above factors to measure the similarity of the acquirer's pipeline drugs with the target's approved drugs.

$$
I_{r, m}(x, y)=\sum_{C_{i} \in\left\{z: z=f\left(P_{i}\right) \forall P_{i} \in P^{x}\right\}} \sum_{C_{j} \in\left\{z: z=f\left(A_{i}\right) \forall A_{i} \in A^{v}\right\}} h\left(d\left(C_{i}, C_{j}\right), s_{r}\left(C_{i}, x\right), s_{m}\left(C_{j}, y\right)\right)
$$

The market expansion factor $E_{m, m}(x, y)$ measures the complementarity of the target's approved drugs to the acquirer's approved drugs. It is given by

$$
E_{m, m}(x, y)=\sum_{C_{j} \in\left\{z: z=f\left(A_{i}\right) \forall A_{i} \in A^{y}\right\}} r\left(d\left(C_{A}^{x}, C_{j}\right), s_{m}\left(C_{j}, y\right)\right)
$$

where $d\left(C_{A}^{x}, C_{j}\right)=\min \left\{d\left(C_{i}, C_{j}\right): C_{i} \in\left\{z: z \in f\left(A_{i}\right) \forall A_{i} \in A^{x}\right\}\right\}$, and the mapping $r: R^{2} \rightarrow R$ is subject to $\frac{\partial r_{m, m}(d, s)}{\partial d} \geq 0$ and $\frac{\partial r_{m, m}(d, s)}{\partial s} \geq 0$. Here $r\left(d\left(C^{x}, C_{j}\right), s_{m}\left(C_{j}, y\right)\right)$ captures the complementarity of the target's approved drugs in therapy class $C_{j}$ to all the approved drugs of 
acquirer in any therapy class. This complementarity factor increases with the minimum distance between $C_{j}$ and the set $C^{x}$ of all therapy classes to which acquirer's approved drugs belong and increases with the market potential of target's approved drugs in $C_{j}$. The market expansion factor is the sum of such complementarity factors across all target therapy classes. This specification aims to capture the new products brought by the target to the acquirer not the other way round.

The $\boldsymbol{R} \& \boldsymbol{D}$ expansion factor $E_{r, r}(x, y)$ is defined similar to the market expansion factor to measure the complementarity of the target's pipeline drugs to the acquirer's pipeline drugs.

$$
E_{r, r}(x, y)=\sum_{C_{j} \in\left\{z: z=f\left(P_{i}\right) \forall P_{i} \in P^{y}\right\}} r\left(d\left(C_{P}^{x}, C_{j}\right), s_{r}\left(C_{j}, y\right)\right)
$$

Table 2 summarizes the above six factors and lists the hypothesis each factor is meant to test.

\section{Model Robustness and Out of Sample Prediction}

We use several methods to test the robustness of our result. First, we perform a bootstrapping procedure on the model to see whether our findings are biased by the small sample. Second, we use the parameter estimates to make out of sample predictions to see whether the inclusion of synergy variables improves the model's predictive power. Third, we test the nonlinearity of product and R\&D intensification factors as suggested in the hypotheses section. Finally, we include financial synergies between the merging firms based on the balance model in Rao, Mahajan and Varaiya (1991). These financial synergies are measured using the dispersion (variance) of the financial variables of the acquirer and the potential target.

\section{Methodological Challenges}

Choice set determination: One challenge in applying the choice model to the acquisition setting is that the researcher does not observe the choice alternatives. The acquiring firm reveals the chosen target but says little about the other firms that were considered for the same deal. In theory, the choice set includes all the pharmaceutical firms existing at the deal announcement 
date. However, our comprehensive synergy measures are too cumbersome to calculate for all the firms in each year. Therefore we adopt the random sampling of alternatives suggested by McFadden (1977) and Train (2003). This method estimates the conditional logit model on a subset of alternatives comprising the true target and a random sample of alternatives selected from the entire alternative pool ${ }^{3}$. A proof from Train (2003, p68-69) included in Appendix A shows that the logit estimation with such sampling of alternatives produces consistent estimates of the true parameters. In Appendix A, we also include the estimation results with this method on simulated data with various sample sizes to support the use of this method for our sample size. The random sampling of alternatives has been used in many situations with the more general nested logit models. Examples include households' choices of automobiles (Mannering and Winston, 1985), households' choices of dwelling location and unit (Weisbrod, Lerman, and BenAkiva, 1980), travelers' choices of destination (Daly, 1982), and the demand for residential telephone service (Train, McFadden and Ben-Akiva, 1987).

Managers' incentives: As corporate finance and agency theories suggest, managers may undertake sub-optimal acquisitions due to empire building or risk diversification motives. To avoid the assumption of optimality, we not only exclude diversifying acquisitions across industries, but also do not include the outside option of not acquiring in the model. In other words, we take the decision to acquire as given and look only at target choice. Even if the acquisition is not entirely optimal, we assume that the managers try to choose the most suitable target after the decision to acquire has been made.

\section{DATA}




\section{Sample and Data Collection Procedure}

Three main pieces of data are used in the empirical analysis: (a) deal related information (b) accounting and financial information for the acquirer and the potential targets; and (c) product and pipeline drugs of the acquirer and the potential targets. The data sources for these three pieces are included in Table 3.

--insert table 3 here-

We select deals between January 2002 and June 2008 where both the acquirer and the target were US public companies in the pharmaceutical industry (SIC code in 2830 category). The reason for restricting the sample to this period is explained in the subsequent paragraphs. The study is restricted to US companies to keep the choice set manageable (it is hard to get comprehensive information on pharmaceutical companies around the world) and to make the accounting data comparable across firms (since accounting standards differ across countries). We choose public acquirers and targets because public firms have relatively complete accounting data. However, we believe our findings can be generalized to private targets as well because a multivariate variance analysis (MANOVA) suggests that acquisition samples with public and private targets are not statistically different from each other ${ }^{4}$. We also delete the deals for which no product and pipeline information can be found in Inteleos. The final observation sample has 29 deals $^{5}$. Since this is a relatively small sample (although it meets the requirement for central limit theorem and the simulations in Appendix A support the random sampling logit estimation for this sample size), we conduct bootstrap analysis to verify the robustness of our findings.

The random sampling of target alternatives discussed in the previous section is done as follows. The full choice set for each deal consists of all US pharmaceutical firms that were publicly owned in the same year or the year before the deal announcement. The full choice set is 
around 500 firms for each deal. For each deal, we keep the target and randomly select 9 other firms from the full choice set for that deal. Data is collected for these subsets of alternatives.

The financial and accounting data is obtained for the quarter ending just before the announcement of a deal. We collect data on 23 relevant variables. Because these variables are highly correlated, we do factor analysis with Varimax rotation to reduce the number of variables. The first three factors explain $75 \%$ of the total variance. We take the variable with the highest factor loading on each of these three factors. The three variables so obtained, namely total assets, book leverage, and return on assets, are used as independent variables in the estimation.

Since Inteleos contains current rather than historical snapshot of product and pipeline data (our data was collected as of June 2008), following steps and approximations are used to recover the product and pipeline status at the time of each deal. First, we purge the approved and pipeline drugs that were acquired by the acquirer and target alternatives through later acquisitions after the deal date in our study ${ }^{6}$. The list of acquisitions by the acquirer and target alternatives after the deal announcement date is obtained from the Capital IQ database. Second, we use the average duration in each clinical phase from DiMasi and Grabowski (2007) ${ }^{7}$ to recover the product and pipeline status of the acquirer and target alternatives on the deal date ${ }^{8}$. Since the average duration between preclinical stage and drug approval is around 6 years, we do not use deals prior to 2002 in our sample because the further back we go back from June 2008 when the data was collected, the less accurate it is to recover the clinical stage of a drug on the deal date. Finally, we obtain the history of any alliances between the acquirer and the target alternatives from the licensing review section in Inteleos database and from SDC Platinum strategic alliance database. 


\section{Summary Statistics}

We present the summary statistics of our sample separately for acquirers, chosen targets, and alternative targets in Table 4. The acquirers range from small firms with $\$ 1.6$ million in assets to very large firms with $\$ 123$ billion in assets. The target firms with median assets of $\$ 186$ million are relatively smaller than the acquiring firms with median assets of $\$ 3.8$ billion.

$$
\text { --Insert Table } 4 \text { here- }
$$

In general, acquirers are more profitable than targets and alternatives. The real targets have larger size, higher return on assets and lower book leverage (debt to assets ratio) than the alternative targets, suggesting that the real targets are financially healthier than the alternative targets on average. The real targets also score higher than the alternative targets on all the six synergy measures, namely market intensification, market expansion, R\&D intensification, $R \& D$ expansion, market to R\&D intensification, and R\&D to market intensification.

\section{Measurement of Synergy}

In this section, we discuss how we adapt the general framewok mentioned in the previous section for calculating the synergies between the acquirer and the target alternatives. All notations refer to the method section. An illustration of the calculation is included in Appendix B.

We do not do hierarchical clustering as mentioned in the previous section because of the significant amount of medical knowledge required to do so. Instead, we use the therapy class tree structure in Inteleos, which has 22,372 therapy classes organized into 10 levels of hierarchy. Since we do not have the distance between therapy classes in Inteleos, we assume that $\forall C_{i} \in C$, $d\left(C_{i}, C_{i}\right)=0, d\left(C_{i}, C_{i}^{p, 1}\right)=0.5$ and $d\left(C_{i}, C_{i}{ }^{p, n}\right)=0.5 n$ where $C_{i}{ }^{p, 1}$ is the immediate parent node and $C_{i}{ }^{p, n}$ is the $n$ level above parent node of $C_{i}$. We also assume that this distance is symmetric $\left(d\left(C_{i}, C_{j}\right)=d\left(C_{j}, C_{i}\right)\right)$ and additive $\left(d\left(C_{i}, C_{j}\right)=d\left(C_{i}, C_{i}^{p, 1}\right)+d\left(C_{i}^{p, 1}, C_{j}\right)\right.$ if $\left.C_{j} \neq C_{i}^{p, n} \forall n\right)$. 
These assumptions specify every distance on the tree. To illustrate the distance calculation, in Figure 1, $d\left(C_{6}, C_{8}\right)=d\left(C_{6}, C_{4}\right)+d\left(C_{4}, C_{8}\right)=d\left(C_{6}, C_{4}\right)+d\left(C_{4}, C_{2}\right)+d\left(C_{8}, C_{2}\right)=0.5+0.5+0.5 * 2=2$, where the first two equalities use the additivity assumption and the third equality uses the assumption $d\left(C_{i}, C_{i}^{p, n}\right)=0.5 n$. Hence, $d\left(C_{i}, C_{j}\right)=1 \forall C_{i} \neq C_{j}$ that share the same immediate parent. The mapping $f: D \rightarrow C$ is obtained from Inteleos which classifies each drug into one or more therapy classes. Since we do not have the data on drug sales, we proxy the market potential of each drug in the mapping $g: D \rightarrow R^{+}$using the clinical probabilities of success in each phase of clinical trial ${ }^{9}$. In particular, approved drugs are given a market score of 1 and pipeline drugs in a given phase are given a R\&D score equal to the clinical probability of approval for that phase.

The similarity factor $h: R^{3} \rightarrow R^{+}$in the intensification factor equations (1)-(4) is specified as:

$$
\begin{aligned}
h\left(d, s_{x}, s_{y}\right) & =\frac{1}{2^{d}}\left(s_{x}+s_{y}\right) & & \text { if } d \leq 2 \\
& =0 & & \text { otherwise }
\end{aligned}
$$

The complementarity factor $r: R^{2} \rightarrow R^{+}$in the expansion factor equations (5)-(6) is given by:

$$
\begin{aligned}
r\left(d, s_{z}\right) & =\frac{1}{2} d s_{z} & & \text { if } d \leq 2 \\
& =s_{z} & & \text { otherwise }
\end{aligned}
$$

These functional forms imply that for $d \leq 2$, the similarity and complementarity factors are almost mirror opposite of each other in terms of sensitivity to distance; for $d>2$, the complementarity factor is capped by $s_{z}$ so as to not amplify the effect of market potential $s_{z}$ on this factor whereas the similarity factor is discontinuous so as to maintain its opposite relation with the former factor.

\section{RESULTS}

The conditional logit estimates are reported in Table 5. As compared to the estimation without the pipeline and market synergy variables (not reported, available upon request), the full 
model estimation in Table 5 improves the McFadden's LRI (a goodness of fit measure) from 0.29 to 0.47 and the Adjusted Estrella (another goodness of fit measure adjusting for number of parameters) from 0.58 to 0.68 . The likelihood ratio test shows that the improvement in log likelihood from -43.21 to -33.57 is statistically significant at 0.01 level (the chi square is 19.28 with 6 degrees of freedom). These results show that the market and R\&D synergy variables increase the model's explanatory power significantly.

--Insert Table 5 here--

The market intensification factor and the R\&D intensification factor (representing $\mathrm{H} 1$ and $\mathrm{H} 3$ respectively) are negatively significant, implying that the acquirers shun targets that simply strengthen their existing markets or R\&D base. The market to R\&D intensification factor and the R\&D to market intensification factor (representing H5 and H6 respectively) are positively significant, implying that the acquirers prefer targets with either approved drugs that match their existing pipeline, or R\&D products that match their existing products.

The positive significance of $R \& D$ to market intensification (H6) suggests that acquirers seek to achieve immediate revenue growth by establishing presence in markets of strategic interest and generate synergy by exploiting the acquired knowledge to improve its $\mathrm{R} \& \mathrm{D}$. The acquirer's pipeline reflects its belief in the marketability of those drugs in the future. However, the acquirer may not want to wait for the slow R\&D process to deliver if it is eager to enter that market. Therefore, the acquirer may choose a target which possesses approved drugs that match the pipeline it is developing. The acquirer can generate synergy by exploiting the knowledge gained from the acquired products to improve its delayed $\mathrm{R} \& \mathrm{D}$ project or create new knowledge.

The positive significance of market to R\&D intensification (H5) suggests that acquirers' seek to boost their long-term innovation potential and generate synergies from pipeline to 
product transformation. An acquirer may want to replenish it pipeline even when its current drugs are generating revenue because current drugs may suffer a loss in revenues once the patent expires, thus resulting in production shutdowns and sales force layoffs. So the acquirer may want to acquire pipeline drugs that could get approved by the time its current drugs run out of patent, and can utilize the existing sales force and production capacity. The acquirer can use its experience and resources to help carry those $R \& D$ projects through the final stages besides providing valuable pre-launch and post-launch support in areas such as production, marketing and sales coverage. Also, an experienced pharmaceutical acquirer can help the target in the FDA's New Drug Application process, which takes an average of 20 months (Berndt 2001).

The above two motives have different planning horizon, with the first one aiming at immediate revenue generation and the second one aiming at promoting innovation to generate revenues few years down the road. Therefore, both considerations can exist in the same deal if the acquirer's pipeline is in some therapeutic areas and its products are in other therapeutic areas. Alternately, the significance of these two motives could be because different deals focus on one of these motives. Unfortunately, the small sample size restricts the further splitting of the sample, since each subset will have too few observations to make the estimation outcome significant.

The negative significance of market and R\&D synergies ( $\mathrm{H} 1$ and $\mathrm{H} 3$ respectively) in our estimation doesn't necessarily contradict the positive results in the empirical literature on "related" mergers (e.g. Amihud and Lev 1981). Instead, the differences may be driven by the degree of "relatedness". The cross-industry studies on "relatedness" consider all firms in the same industry as related whereas we capture the "relatedness" within an industry. So the findings in the literature may hold that mergers in the same industry are more likely to create synergy, but within an industry, it seems the acquirers don't want targets that are similar to themselves. The 
bell shaped effect between relatedness and synergy (Prabhu, Chandy and Ellis 2005) might peak at the boundary of the industry, and generate the results found in the literature and in this paper.

We do not find significant evidence for the market and R\&D expansion factors $(\mathrm{H} 2$ and $\mathrm{H} 4$ respectively). This finding does not necessarily mean that the acquiring firms do not use acquisition as an expansion tool. Instead, it might be that acquirers have certain aims in their market or $R \& D$ expansions. In particular, $R \& D$ to market intensification is a subset of $R \& D$ expansion because the complementarity of target's R\&D to acquirer's R\&D doesn't preclude the possibility that the target's R\&D could be similar to acquirer's markets. Using the same logic, market to R\&D intensification is a subset of market expansion. Since the acquirer needs expertise in the area it wants to enter to assimilate the new products and knowledge, it may want to expand in areas that it is familiar with (positive significance of interaction synergies) instead of expanding in totally new areas (lack of significance of expansion synergies).

As for the other variables, none of the culture matching variables turn out to be significant. This is more or less expected, because "culture" of a firm is always difficult to define, not to mention quantify. The return on assets of the target firm is a significant factor for target selection. Obviously target firms with higher returns are more attractive to acquirers. Targets greater than 10 billions are less likely to be selected, which confirms our conjecture that challenges specific to large firm acquisition such as difficulty in integration and culture shock hold back acquirers from acquiring these large targets.

\section{Bootstrapping Test}

We conduct a bootstrap study pioneered by Efron (1979) to verify the robustness of our findings. Following the standard bootstrap procedure in Mooney and Duval (1993), we draw 1000 times, 29 observations with replacement from the original sample, and calculate summary 
statistics for the 1000 parameter estimates. Table 6 contains the mean, median and confidence interval of the parameter estimates. Our findings from the main estimation regarding market and R\&D synergies hold in the Bootstrap study.

--Insert Table 6 here--

\section{Predictive Power}

We do the following analysis to test the out of sample predictive power of the model: 1) remove 2 deals from the 29 deals ,2) run the conditional logit estimation with the remaining 27 deals and estimate the parameters, 3) use the parameter estimates to predict the target for the two deals that were dropped from the estimation sample, 4) record the accuracy of the prediction, and 5) repeat steps 1-4 for all possible combinations of 2 deals out of 29, which is 406 in total (we use 2 deals instead of 1 in each round, because the former gives us a much larger sample for statistical testing). With the six market and R\&D synergy variables, the accuracy of the model prediction is $54.56 \%$, whereas the accuracy without these synergies is $44.46 \%$ (the difference is statistically significant at 0.01 level). The chance of random selection is $10 \%$. These test shows that the model does a significantly better job than chance in predicting target choice. And the inclusion of market and R\&D synergies improves the model's predictive power significantly as compared to having financial variables alone.

\section{Tests for Nonlinearity of R\&D and Market Intensification}

We include the square term of the R\&D intensification factor together with the first order term in the estimation to see whether a bell-shaped effect of the R\&D intensification factor exists (results not reported, available upon request). The effect of R\&D intensification does not change: neither the first order term nor the square term is significant. However, the effect of market intensification changes with the inclusion of its square term: the market intensification fator is 
positively significant and its square term is negatively significant. This result may be arising due to the positive correlation between the pipeline and approved drugs of the acquirers. To test this conjecture, we include the market and R\&D intensification and expansion factors together with the square term of the market intensification factor in the estimation. The market intensification factor is negatively significant and the square term is not significant, confirming our conjecture that correlation is driving the non-linear effect of market intensification in the earlier estimation.

\section{Test for Financial Synergies:}

To verify the effect of financial synergies proposed by Rao et al (1991), we include the dispersion of financial variables of the acquirer and target alternatives in the main estimation. Our findings from the main estimation are unchanged in this new specification. And none of the financial synergy variables is significant (results not reported, available upon request). The goodness of fit measured by McFadden's LRI increases from 0.47 to 0.49 , which means that the

financial synergy variables increase the explanatory power; however, the Adjusted Estrella decreases from 0.73 to 0.67 after the increased number of independent variables are taken into account. While the financial synergy may explain some of the "fit" between acquirers and targets, our market and R\&D synergy variables are much more refined measures of synergy between the merging firms, and therefore overshadow the significance of financial synergy.

\section{DISCUSSIONS AND IMPLICATIONS}

Our findings provide considerable support for the knowledge based view of the firm. Knowledge, in the form of product knowledge and R\&D knowledge, is a strong motivation for acquisition target selection. This point has been suggested by the competence based theories of the firm (of which knowledge based view of the firm is a subset) and has had a strong influence 
on the M\&A literature (e.g. Hamel and Prahalad 1994, Haspeslagh and Jemison 1991). As the organization is dependent on the current and aspired configuration of capabilities, these capabilities influence the extent of mergers and acquisitions by determining the boundaries of the firm and acting as the first and foremost decision-making determinant in the M\&A due diligence process. Even more generally, resource endowments and synergy seeking can be argued to influence pre-merger processes like growth strategy selection, candidate selection, strategic and financial due diligence as well as negotiations. In this empirical study we find concrete support for this school of thought.

Although this research is conducted in the pharmaceutical industry, the findings can be generalized to many high tech industries that emphasize on innovation and have frequent consolidation through acquisition. For example, similar acquisition patterns can be found in the information technology industry where firms such as Microsoft, Google and Cisco have acquired successful products in new markets where these giants wanted to enter (for instance, Google acquired the popular "You Tube" while its "Google Video" was struggling to enter this market).

This research can help managers in several ways. It provides the acquiring firm a viable tool to quantify its potential synergy with a target. The manager's qualitative guidelines of "strategic fitness" can be quantified using our synergy measures and the fit with different potential targets can be compared to choose the best target. Managers can enhance our synergy measures by including more variables such as, geographic regions, market shares, sales figures, sales force expertise, distribution coverage, management and scientific personnel, etc. Better measures for cultural fit can also be included in anticipation of the integration process. Also, the framework in this paper can be adapted by executives to make other business to business relationship decisions such as the choice of an advertising firm. 


\section{LIMITATIONS AND DIRECTIONS FOR FUTURE RESEARCH}

There are several limitations of this paper. First, since the reasons for acquisition often differ across industries, certain effects in a single industry study may be counter-effected in cross industry studies. More empirical studies are needed using data from other industries with different levels of reliance on innovation. Second, within our application context, we do not have detailed information on production facilities, sales force, market share, etc. Although our synergy measures serve as a proxy for these operational factors, including these explicit measures can verify the findings in this paper. Third, as in most empirical studies, we assume the same acquisition incentive across deals. It is possible that different acquisitions are conducted for different reasons, even within the same industry. With a larger dataset and more readily available pipeline and product information, one can test more refined hypotheses on acquisition incentives specified by acquirer types. For example, this heterogeneity can be introduced through acquirer specific parameters with different distributional assumptions and estimated through Hierarchical Bayesian methods.

As for future research, our choice modeling in an acquisition context can be extended by researchers to study other managerial decisions in the Business to Business context, such as alliances and joint vetures, where the needs of both the initiator and the recipient are to be considered, and the best results can be achieved through synergy creation. The model can also be generalized by researchers in many non-business settings, such as dating and social networking.

This paper also suggests a new direction for the empirical acquisition literature. Instead of studying the acquisition outcome unconditionally, this paper suggests that it might be better to condition the outcome on acquisition motive. The knowledge of acquirer's motive can help in 
deciding which aspect of acquisition outcome to evaluate. For instance, if an acquirer chooses a target whose pipeline can deliver products in 5 years time, it is not useful to evaluate the acquisition based on earnings growth in 3 years time. Controlling for target selection in the acquisition outcome can also help in ascertaining the impact of integration process because the inability of achieving the acquirer's initial motives must be due to an unsuccessful integration. 


\section{$\underline{\text { References: }}$}

Ahuja, Gautam and Riitta Katila (2001), "Technological acquisitions and the innovation performance of acquiring firms: a longitudinal study," Strategic Management Journal, 22(3), 197-220.

Amihud, Y. and B. Lev. (1981), "Risk reduction as a managerial motive for conglomerate mergers: a transaction cost analysis," Bell Journal of Economics 12: 605-616.

Anderberg, M.R. (1973), Cluster Analysis for Applications, New York: Academic Press, Inc.

Andrade, Gregory, Mark Mitchell, and Erik Stafford (2001), "New Evidence and Perspectives on Mergers," Journal of Economic Perspectives, 15 (2), 103-20.

Andrade, Gregory and Erik Stafford (2004), "Investigating the Economic Role of Mergers," Journal of Corporate Finance, 10, 1-36.

Berndt, Ernst R. (2001), "The U.S. Pharmaceutical Industry: Why Major Growth In Times of Cost Containment?" Health Affairs, 20(2), 100-114.

Bierlaire, M., D. Bolduc, and D. McFaden (2006), "The Estimation of Generalized Extreme Value Models from Choice-based Samples," Transportation Research Part B: Methodogical 42(4): 381394.

Mooney, Christopher and Robert Duval (1993), "Boostrapping a Nonparametric Approach to Statistical Inference," Newbury Park, California: Sage Publications.

Cohen, W. and Levinthal D (1990), "Absorptive Capacity: A new Perspective on Learning and Innovation," Administrative Science Quarterly, 35: 128-152.

Daly, A. (1982), "Estimating Choice Models Containing Attraction Variables," Transportation Research, 16B, 5-15.

Danzon, Patricia M., Andrew Epstein, and Sean Nicholson (2007), "Mergers and Acquisitions in the Pharmaceutical and Biotech Industries," Managerial and Decision Economics, 28, 1-22. 
DiMasi, JA, HG Grabowski,(2007) "The cost of biopharmaceutical R\&D: is biotech different?",Managerial and Decision Economics,28(4-5), P469 - 479

Efron, B. (1979), “Bootstrap Methods: Another look at the Jackknife,” Annals of Statistics, 7(1), 1-26.

Foss, K. \& N.J. Foss. (2000), "Learning in Firms: Knowledge-Based and Property Rights Perspectives," Working paper, Copenhagen Business School

Hagedoorn, J. \& B.M. Sadowski (1999), "The transition from strategic technology alliances to mergers and acquisitions: an exploratory study," Journal of Management Studies 36(1): 87-107

Haleblian, J. \& S. Finkelstein (1999), "The influence of organizational acquisition experience on acquisition performance: a behavioral learning perspective," Administrative Science Quarterly 44: 29-56.

Hamel, G. \& C.K. Prahalad, (1994), Competing for the Future. Boston, Mass.: Harvard Business School Press.

Haspeslagh PC and DB Jemison (1991), "Managing Acquisitions: Creating Value through Corporate Renewal," New York: Free Press.

Henderson R and I. Cockburn (1994), "Measuring Competence? Exploring Firm Effects in Pharmaceutical Research," Strategic Management Journal, 15 (Winter), 63-84.

Higgins, Matthew J. and Daniel Rodriguez (2006), "The Outsourcing of R\&D through Acquisitions in the Pharmaceutical Industry," Journal of Financial Economics, 80, 351-83.

Homburg, Christian and Matthias Bucerius (2005), “A Marketing Perspective on Mergers and Acquisitions: How Marketing Integration Affects Postmergers Performance”.Journal of Marketing, 69(1), 95-113.

Jemison, D.B. \& S.B. Sitkin (1986), “Corporate Acquisitions: A Process Perspective,” Academy of Management Review 11(1): 145-163. 
Johnson, S.C. (1967), “Hierarchical Clustering Schemes,” Psychometrika, 32, 241-254.

Kabiraj, T. \& A. Mukherjee (2000), "Cooperation in R\&D and production: a three firm analysis," Journal of Economics 71: 281-304.

Kogut, B. and U. Zander. (1992), "Knowledge of the firm, combinative capabilities, and the replication of technology," Organization Science, 3: 383-397.

Kroll, Mark and Stephen Caples (1987), "Managing Acquisitions of Strategic Business Units with the Aid of the Arbitrage Pricing Model," Academy of Management Review, 12, 676-85.

Leonard-Barton Dorothy (1995), Wellsprings of Knowledge. Boston: Harvard Business School Press.

Levine, A. (2007), "Licensing and Scale Economies in the Biotechnology Pharmaceutical Industry," dissertation essay, Stanford University.

Loughran, Tim and Anand Vijh (1997), "Do Long-Term Shareholders benefit from Corporate Acquisitions?" The Journal of Finance, 52, 1765-1790.

Lubatkin Michael (1983), "Mergers and the Performance of the Acquiring Firm," Academy of Management Review, 8(2), 218-225.

Mannering, F. and Winston, C. (1985), “A Dynamic Empirical Analysis of Household Vehicle Ownership and Utilization,” Rand Journal of Economics, 16, 215-236.

McFadden, Daniel (1973), Conditional Logit Analysis of Qualitative Choice Behaviour, P. Zarembka (Ed.), Frontiers in Econometrics. New York: Academic Press.

McFadden, Daniel (1977), "Modeling the Choice of Residential Location," working paper, Yale University.

Parvinen, Petri (2003), “Towards a Governance Perspective to Mergers and Acquisitions,” Doctoral Dissertation, Helsinki University of Technology. 
Porter, M.E. (1987), "From competitive advantage to corporate strategy," Harvard Business Review 65: 43-59.

Porter, Michael E. (1980), "Competitive Strategy," New York: NY: the Free Press.

Prabhu, Jaideep, Rajesh Chandy and Ellis, Mark E.(2005),’The Impact of Acquisitions on Innovation: Poison Pill, Placebo, or Tonic?”, Journal of Marketing, 69(1):114-130

Rao, Vithala, Vijay Mahajan, Nikhil P. Varaiya (1991), “A Balance Model for Evaluating Firms for Acquisitions", Management Science, 37(3): 331-349

Richter, A. (1999), Corporate Restructuring in the United Kingdom and West Germany: Recent Developments in Large Non-Financial Companies. London: London School of Economics and Political Science.

Rindfleisch, Aric and Christine Moorman (2001), "The Acquisition and Utilization of Information in New Product Alliances: A Strength-of-Ties Perspective," Journal of Marketing, 65 (April) 1-18. Rumelt, R.P. (1974), Strategy, Structure and Economic Performance. Boston: Harvard University Press

Salter, M. and Weinhold W., (1979), Diversification through Acquisition, New York: Free Press.

Sattath, S. and Tversky A., (1977), “Additive similarity trees”, Psychometrika, 42, 319-345.

Schniederjans, M. J. and Karen F. L., (1989), "Strategic Acquisitions Management: A Multi-Objective Synergistic Approach," The Journal of the Operational Research Society, 40(4), 333-45.

Schumpeter, Joseph A. (1942), Capitalism, Socialism, and Democracy, New York and London: Harper \& Brothers Publishers.

Shepherd, William G. (1970), Market Power and Economic Welfare: An Introduction, NY: Random House. 
Shepherd, William G.(1979), Economics of Industrial Organization, Englewood Cliffs, N.J.: PrenticeHall.

Silhan, Peter A. and Howard Thomas (1986), "Using Simulated Mergers to Evaluate Corporate Diversification Strategies," Strategic Management Journal, 7, 523-34.

Simon, Herbert A. (1991), "Bounded Rationality and Organizational Learning," Organization Science, 2: $125-134$.

Singh, H. \& C.A. Montgomery. (1987), "Corporate acquisition strategies and economic performance," Strategic Management Journal 8: 377-386.

Sneath, P.H.A. and Sokal, R.R. (1973), Numerical Taxonomy, San Francisco: Freeman.

Sorescu, Chandy, and Prabhu (2007), "Why some acquisitions do better than others: Product capital as a driver of long-term stock returns,"Journal of Marketing Research, 44(1),57-72.

Swaminathan, Vanitha, Feisal Murshed, and John Hulland (2008), "Value Creation Following Mergers and Acquisitions Announcements: The Role of Strategic Emphasis Alignment", Journal of Marketing Research, 45(1): 989-999.

Train K. E. (2003), "Discrete Choice Methods with Simulation," Cambridge University Press.

Train, Kenneth E., Daniel L. McFadden and Moshe Ben-Akiva (1987), “The demand for local telephone service: a fully discrete model of residential calling patterns and service choices,”, Rand Journal of Economics, 18(1), 109-123.

Trautwein, Friedrich (1990), "Mergers Motives and Mergers Prescriptions," Strategic Management Journal, 11 (4), 283-95.

Walter, Gordon A. and Jay B. Barney (1990), "Research notes and Communications Management Objectives in Mergers nd Acquisitions," Strategic Management Journal, 11, 79-86. 
Weisbrod, G., Lerman, S., and Ben-Akiva, M. (1980), “Tradeoffs in Residential Location Decisions: Transportation versus Other Factors," Transport Policy and Decision-making, 1, 13-26. Wernerfelt, Birger and Cynthia A. Montgomergy (1988), "Tobin's q and the Importance of Focus in Firm Performance," American Econmic Reivew, 78(1), 246-51.

Weston, J. F., M.L. Mitchell and J.H. Mulherin (2004), Takeovers, Restructuring, and Corporate Governance, 4th ed. Pearson Education Inc., Upper Saddle River, N.J.: Prentice Hall. 


\section{Footnotes:}

1. Case studies show that many acquirers fail to materialize the promised synergies (Porter 1987). The stock return of combined firm is shown to be positive in the short-term (Andrade and Stafford 2004) and negative in the long-run (Loughran and Vijh 1997). The impact of acquisitions on R\&D is shown to be positive (Weston, Mitchell and Mulherin 2004).

2. We did an extended review of M\&A theories including strategy theories, process theories, financial theories, governance theories and competence- based theories (including resourcebased and knowledge-based views of the firm). Web appendix B discusses these theories and their relevance to this paper in details.

3. According to Train (2003), "With a logit model, consistent estimation can be performed on a subset of alternatives. For example, a choice situation involving 100 alternatives can be estimated on a subset of 10 alternatives for each sampled decision maker, with the person's chosen alternative included as well as 9 alternatives randomly selected from the remaining 99 . The estimation proceeds on the subset of alternatives as if it were the full set."

4. We conducted individual and joint MANOVA tests on public and private samples based on four financial ratios, namely sales ratio; total assets ratio; current assets ratio; and liability ratio (calculated as target value/acquirer value). None of the tests reject the null hypothesis that the two samples are not different from each other. Results are available upon request.

5. SDC Platinum contains 644 acquisition deals in the Pharma industry between January 2002 and June 2008. Of these, 594 deals dropped out because the acquirer or the target is not a public firm. Additional 20 deals dropped out due to missing product and pipeline information in Inteleos. Finally, one deal is dropped as an outlier because the target is unusually larger the acquirer (their ratio is more than two standard deviations higher than the historical mean). 
6. In some cases the target firm is not directly available in Inteleos after the acquisition because Inteleos counts the acquired drugs as acquirer's. However, Inteleos puts a note to this effect in the licence overview of the acquirer's drugs. In such cases, we obtain the target pipeline by searching the target firm's name in the license overview section of the acquirer's drugs.

7. The average duration of preclinical, phase I, phase II, phase III, and pending approval stages are $5.03,1.80,2.14,2.54$, and 1.52 years respectively.

8. For example, if the deal took place in Jan 2002 and Inteleos shows that a target has a drug that was approved in May 2007, then we move backwards in time using the average duration of each phase and conclude that this drug most likely must have been in Phase 2 in Jan 2002.

9. Following Higgins and Rodriguez (2006), we study all the five phases of drug development namely Pre-clinical, Phase I, Phase II, Phase III, and Pending Approval. The clinical probabilities of approval in these phases are $0.07,0.22,0.30,0.69$, and 0.9 respectively. 


\section{Tables}

Table 1: Synergy Measures in Merger and Acquisition Literature ${ }^{a}$

\begin{tabular}{|c|c|c|c|c|c|}
\hline & $\begin{array}{l}\text { Market } \\
\text { Similarity }\end{array}$ & $\begin{array}{l}\text { Market } \\
\text { Complementarity }\end{array}$ & $\begin{array}{l}\text { R\&D } \\
\text { Similarity }\end{array}$ & $\begin{array}{l}\text { R\&D } \\
\text { Complementarity }\end{array}$ & $\begin{array}{l}\text { Market and R\&D } \\
\text { Interactions }\end{array}$ \\
\hline Singh and Montgomery $(1987)^{b}$ & yes & & yes & & \\
\hline Harrison et al.(1991) ${ }^{c}$ & & & yes & yes & \\
\hline 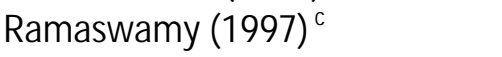 & yes & yes & & & \\
\hline Hitt et al. (1998) & yes & & maybe & & \\
\hline Larsson and Finkelstein (1999) & yes & yes & & & \\
\hline Swaminathan at el. (2008) ${ }^{d}$ & yes & & yes & & \\
\hline Prabhu et al.(2005) & & & yes & & \\
\hline Sorescu et al. (2007) & yes & & & & \\
\hline This paper ${ }^{\mathrm{e}}$ & yes & yes & yes & yes & yes \\
\hline
\end{tabular}

a. We acknowledge that the papers in this table may have contributions other than synergy measurement. Here we merely intend to illustrate the design of synergy measures in the literature, with no intention to undermine the contributions of these papers.

b. Similar measures are shared by Shalton (1988) and Datta, Pinches, and Narayanan (1992).

c. In these papers the "similarity" measure is a distance measure, and the complementarity is considered to be the opposite of similarity. Therefore, one measure is counted for two aspects.

d. In this paper the synergy measureme is "Strategic emphasis alignment", which is absolute difference between the acquirer and target strategic emphasis [(advertising expenditures - R\&D expenditures)/total assets of the firm].

e. The current paper uses different measures for similarity and complementarity. Our measures for complementarity capture the new products or knowledge that the potential target brings to the acquirer, not the other way round. Therefore, our similarity and complementarity measures are not polar opposite of each other. 


\section{Table 2: Explanation of Variables}

\section{Parameters}

First component: financial variables

Total Assets

Debt to Asset Ratio (DTA)

Return on Assets (ROA)

Second component: control variables

Large_dummy

Alliance_dummy

Biotechnology

Sales Ratio

SIC Matching

Third component: synergy variables

Product and Pipeline synergies

Market Intensification

Market Expansion

R\&D Intensification

R\&D Expansion

Market to R\&D Intensification

R\&D to Market Intensification

Financial synergies

$(\text { Assets_a - Assets_t })^{\wedge} 2$

$(\text { DTA_a - DTA_t })^{\wedge} 2$

$(\text { ROA_a - ROA_t })^{\wedge} 2$

\section{Explanation}

potential target firms' annual sales (billion \$)

potential target firm's total liabilities over total assets

potential target firm's net income over total shareholder equity

dummy variable representing firms with market value greater than 10 billion dollars

dummy variable indicating that the alternative had alliance relationship with the acquirer firm prior to the acquisition

Dummy variable for biotechnology focus, proxy for scientific culture

Ratio of target sales to Acquirer sales, proxy for organizational culture

Dummy indicaing whether the acquirer and target are in the same SIC category, proxy for market culture

similarity between acquirer and alternative based on approved drugs (for H1)

complementarity between acquirer and alternative based on approved drugs (for $\mathrm{H} 2$ )

similarity between acquirer and alternative based on pipeline (for H3)

complementarity between acquirer and alternative based on pipeline (for H4)

similarity between acquirer's products and target's pipeline (for H5)

similarity between acquirer's pipeline and target's products (for H6)

dispersion of acquirer's and potential target's total assets

dispersion of acquirer's and potential target's debt-to-asset ratio

dispersion of acquirer's and potential target's return of assets 


\section{Table 3: Data Sources}

\begin{tabular}{|c|c|c|}
\hline Information Description & Variables & Data source \\
\hline Deal related information & $\begin{array}{l}\text { Deal date; acquirer and target firm name, public } \\
\text { status, industry SIC code, deal purpose; etc. }\end{array}$ & SDC Platinum* M\&A \\
\hline Financial information & Sales, assets, liabilities, market value, etc. & Compustat \\
\hline $\begin{array}{l}\text { Full choice set of } \\
\text { potential targets }\end{array}$ & List of public pharma firms in 2001-2008 & Compustat \\
\hline $\begin{array}{l}\text { Product and pipeline } \\
\text { information }\end{array}$ & $\begin{array}{l}\text { Each firm's approved and pipeline drugs in all clinical } \\
\text { stages }\end{array}$ & Inteleos $^{* *} /$ Capital IQ \\
\hline Alliance Information & Dummy for alliance history & $\begin{array}{l}\text { SDC Platinum Strategic } \\
\text { Alliance/Capital IQ }\end{array}$ \\
\hline
\end{tabular}

* SDC Platinum is a professional dataset offered by Thomson Financial

* Inteleos ${ }^{\mathrm{TM}}$ (online version of NDA Pipeline) is a commercial database provided by Elsevier that tracks the drug development activity from late-stage preclinical through launch and post-marketing studies. It is updated daily and has coverage of more than 8000 drugs from more than 1200 companies. 
Table 4: Summary statistics for acquirer, target and alternative target firms

\begin{tabular}{|c|c|c|c|c|c|c|}
\hline \multirow[b]{2}{*}{ Variable } & \multicolumn{3}{|c|}{ Target } & \multicolumn{3}{|c|}{ Alternatives } \\
\hline & Mean & Std Dev & Median & Mean & Std Dev & Median \\
\hline Assets (Million \$) ${ }^{\mathrm{a}}$ & 1047.76 & 4107.63 & 186.78 & 449.96 & 2300.66 & 41.76 \\
\hline Return on Assets(ROA) ${ }^{b}$ & -0.06 & 0.12 & -0.04 & -0.28 & 0.89 & -0.12 \\
\hline Book Leverage $(B L)^{c}$ & 0.45 & 0.67 & 0.23 & 0.71 & 1.55 & 0.35 \\
\hline Large & 0.03 & 0.19 & 0 & 0.01 & 0.11 & 0 \\
\hline Alliance & 0.21 & 0.41 & 0 & 0.01 & 0.09 & 0 \\
\hline Market Intensification & 131.07 & 571.18 & 0 & 49.29 & 381.23 & 0 \\
\hline Market Expansion & 2.06 & 5.99 & 0 & 0.77 & 3.66 & 0 \\
\hline R\&D Intensification & 355.26 & 1162.91 & 36.96 & 208.52 & 752.32 & 8.77 \\
\hline R\&D Expansion & 2.54 & 4.72 & 0.64 & 1.44 & 2.96 & 0.25 \\
\hline Market to $R \& D$ Intensification & 184.59 & 602.89 & 4.82 & 110.95 & 470.12 & 3.21 \\
\hline$R \& D$ to Market Intensification & 235.62 & 957.12 & 0 & 67.97 & 502.33 & 0 \\
\hline Biopharma & 0.28 & 0.45 & 0 & 0.4 & 0.49 & 0 \\
\hline Sales Ratio & 0.27 & 0.59 & 0.03 & 0.1 & 0.36 & 0 \\
\hline SIC Match & 0.59 & 0.5 & 1 & 0.44 & 0.5 & 0 \\
\hline$(\text { Assets_a-Assets_t })^{\wedge} 2$ & $1.73 \mathrm{E}+09$ & $4.36 \mathrm{E}+09$ & $1.59 \mathrm{E}+07$ & $1.77 \mathrm{E}+09$ & $4.20 \mathrm{E}+09$ & $1.73 \mathrm{E}+07$ \\
\hline$(\mathrm{ROA} a-\mathrm{ROA}+\mathrm{t})^{\wedge} 2$ & 0.02 & 0.04 & 0 & 0.85 & 8.99 & 0.02 \\
\hline$\left(\mathrm{BL} a-\mathrm{BL} \_\mathrm{t}\right)^{\wedge} 2$ & 0.69 & 2.2 & 0.07 & 2.49 & 20.77 & 0.06 \\
\hline
\end{tabular}


Table 5 Parameter Estimates

\begin{tabular}{lrrrr}
\hline Parameter & Parameter Estimate & Standard Error & t Value & Pr $>|\mathbf{t}|$ \\
\hline Total Assets & $4.51 \mathrm{E}-04$ & $6.79 \mathrm{E}-04$ & 0.66 & 0.51 \\
Return on Assets & 4.73 & 2.55 & 1.86 & 0.06 \\
Book Leverage & -1.37 & 0.96 & -1.42 & 0.15 \\
Market Intensification & -0.05 & 0.02 & -2.36 & 0.02 \\
Market Expansion & 0.04 & 0.14 & 0.31 & 0.76 \\
R\&D Intensification & -0.02 & 0.01 & -2.23 & 0.03 \\
R\&D Expansion & 0.05 & 0.07 & 0.69 & 0.49 \\
Market to R\&DIntensification & 0.03 & 0.01 & 2.42 & 0.02 \\
R\&D to Market Intensification & 0.04 & 0.02 & 2.52 & 0.01 \\
Alliance & 29.84 & 4681 & 0.01 & 0.99 \\
Large & -54.8 & 30.26 & -1.81 & 0.07 \\
SIC Matching & 0.97 & 0.59 & 1.63 & 0.1 \\
Sales Ratio & 0.39 & 0.52 & 0.74 & 0.46 \\
Biopharma Matching & -0.3 & 0.57 & -0.52 & 0.6 \\
\hline
\end{tabular}

Notes:

a. Number of obs: 29; Number of cases: 264

b. McFadden's LRI: 0.47 . This is a goodness of fit analogous to the $R_{2}$ in the linear regression model. $R_{M}^{2}=1$ $\left[\operatorname{lnL} /\left(\ln \mathrm{L}_{0}\right)\right]$ where $\mathrm{L}$ is the maximum of the $\log$-likelihood function and $\mathrm{L}_{0}$ is the maximum of the $\log$-likelihood function when all coefficients, except for an intercept term, are zero. McFadden's likelihood ratio index is bounded by 0 and 1 .

c. Adjusted Estrella: 0.73 . Adjusted Estrella is another goodness of fit measurement suggested by Estrella: RE22 = $1-[(\operatorname{lnL}-\mathrm{K}) / \operatorname{lnL} 0]-(2 / \mathrm{N}) \operatorname{lnL} 0$, where $\operatorname{lnL} 0$ is computed with null parameter values, $\mathrm{N}$ is the number of observations used, and $\mathrm{K}$ represents the number of estimated parameters. 
Table 6 Bootstrap Analysis

\begin{tabular}{lrrrr}
\hline Parameters & Mean & Median & 5th percent & 95th Percent \\
\hline Total Assets & $-4.98 \mathrm{E}-03$ & 0.00 & -0.00333 & 0.00273 \\
Return on Assets & 45.79 & 6.08 & 1.02 & 28.3 \\
Book Leverage & -3.87 & -2.39 & -8.27 & -0.6 \\
Market Intensification & -0.46 & -0.08 & -0.5 & -0.03 \\
Market Expansion & 0.14 & 0.02 & -0.41 & 0.76 \\
R\&D Intensification & -0.09 & -0.02 & -0.06 & 0 \\
R\&D Expansion & 0.06 & 0.02 & -0.24 & 0.37 \\
Market to R\&D Intensification & 0.18 & 0.03 & 0.01 & 0.13 \\
R\&D to Market Intensification & 0.33 & 0.06 & 0.03 & 0.26 \\
Alliance & 118.93 & 33.26 & 21.1 & 120.52 \\
large & -149.78 & -62.41 & -303.52 & 214.6 \\
SIC Matching & 3.24 & 0.98 & -0.29 & 2.81 \\
Sales Ratio & 22.15 & 0.36 & -1.62 & 8.89 \\
Biopharma Matching & -2.78 & -0.59 & -2.65 & 0.36 \\
\hline
\end{tabular}


Figure 1: An Illustration of Proximity Tree

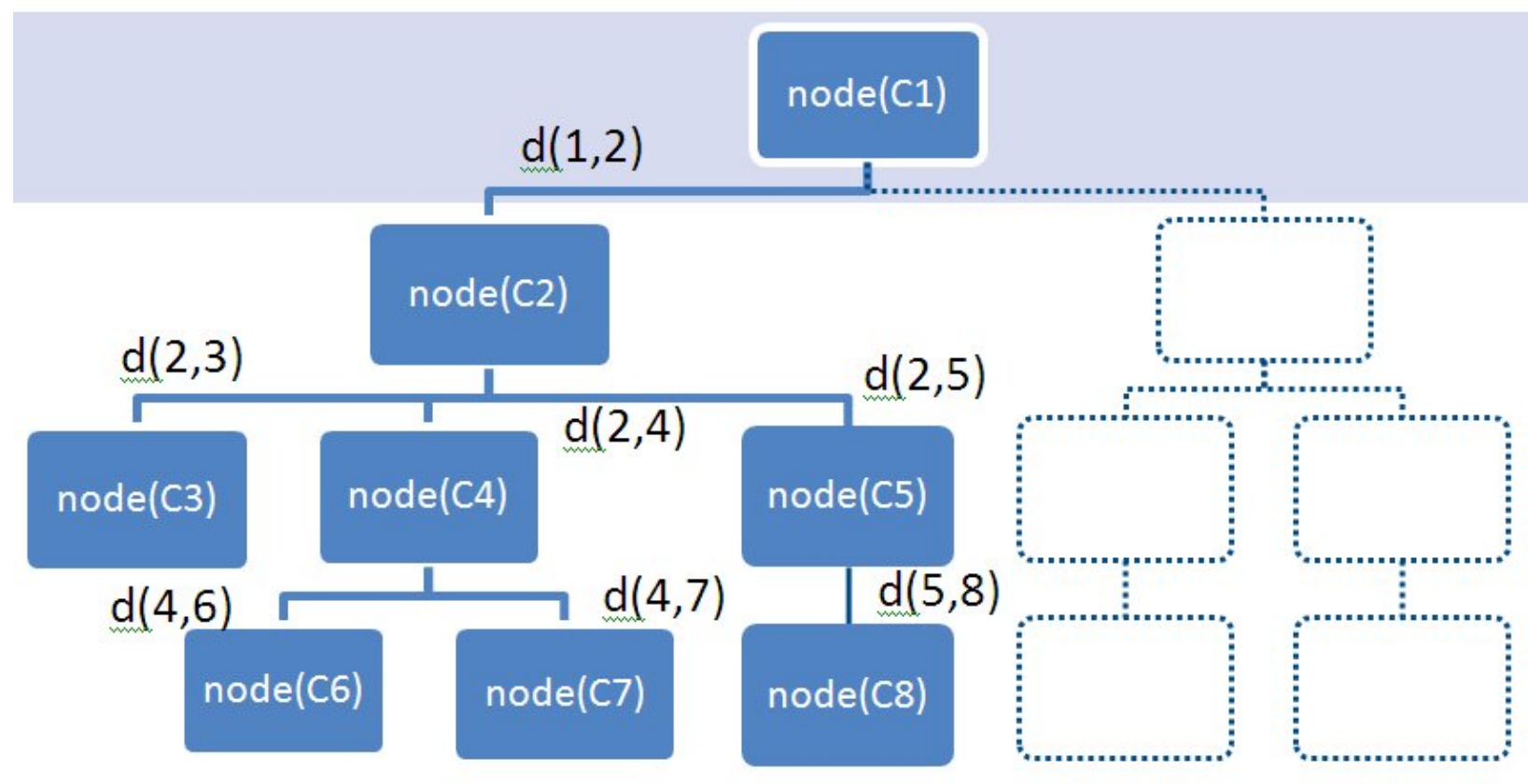




\section{Appendix A: Logit Estimation with Randomly Sampled Alternatives Proof of consistency:}

This section reproduces a proof from Train (2003) regarding the consistency of logit estimation with randomly sampled alternatives. The next section contains simulation results with different sample sizes.

Suppose that the researcher has used some specific method for randomly selecting alternatives into the subset that is used in estimation for each sampled decision maker. Denote the full set of alternatives as $F$ and a subset of alternatives as $K$. Let $q(K \mid i)$ be the probability under the researcher's selection method that subset $K$ is selected given that the decision maker chose alternative $i$. Assuming that the subset necessarily includes the chosen alternative, we have $q(K \mid i)=0$ for any $K$ that does not include $i$. The probability that person $n$ chooses alternative $i$ from the full set is Pni. Our goal is to derive a formula for the probability that the person chooses alternative $i$ conditional on the researcher selecting subset $K$ for him. This conditional probability is denoted $\operatorname{Pn}(i \mid K)$. This conditional probability is derived as follows. The joint probability that the researcher selects subset $K$ and the decision maker chooses alternative $i$ is $\operatorname{Prob}(K, i)=q(K \mid i) P_{n i}$. The joint probability can also be expressed with the opposite conditioning as $\operatorname{Prob}(K, i)=\operatorname{Pn}(i \mid K) Q(K)$ where $Q(K)=j \square F q(K \mid j) P n j$ is the probability of the researcher selecting subset $K$ marginal over all the alternatives that the person could choose. Equating these two expressions and solving for $\operatorname{Pn}(i \mid K)$, we have

$$
P n(i ; K)=\frac{P_{n i} q(K \mid i)}{\sum_{j \in F} P_{n j} q(K \mid j)}=\frac{e^{V_{n i}} q(K \mid i)}{\sum_{j \in F} e^{V_{n j}} q(K \mid j)}=\frac{e^{V_{n i}} q(K \mid i)}{\sum_{k \in K} e^{V_{n k}} q(K \mid j)}
$$

where the second line has canceled out the denominators of $P_{n i}$ and $P_{n j} \forall j$, and the third equality uses the fact that $q(K \mid j)=0$ for any $j$ not in $K$. 
Suppose that the researcher has designed the selection procedure so that $q(K \mid j)$ is the same for all $j \in K$. This property occurs if, for example, the researcher assigns an equal probability of selection to all non-chosen alternatives, so that the probability of selecting $j$ into the subset when $i$ is chosen by the decision maker is the same as for selecting $i$ into the subset when $j$ is chosen. McFadden (1977) calls this the "uniform conditioning property," since the subset of alternatives has a uniform (equal) probability of being selected conditional on any of its members being chosen by the decision maker. When this property is satisfied, $q(K \mid j)$ cancels out of the preceding expression, and the probability becomes: $\operatorname{Pn}(i \mid K)=e^{V_{n i}} /\left(\sum_{j \in k} e^{V_{n j}}\right)$, which is simply the logit formula for a person who faces the alternatives in subset $K$.

\section{Simulation with different sample sizes}

We do a simulation to study the ability of the model to recover parameters with different sample sizes and different number of true alternatives. In this simulation, we assume a utility function of the form $\mathrm{U}=\mathrm{b} 1 * \mathrm{x} 1+\mathrm{b} 2 * \mathrm{x} 2+\mathrm{e}$, where $\mathrm{x} 1$ and $\mathrm{x} 2$ are object attributes, and $\mathrm{e}$ is an error term following extreme value distribution with shift 0 and scale 1 . The true values used for b1 and $\mathrm{b} 2$ are 1 and 2 respectively, and $\mathrm{x} 1$ and $\mathrm{x} 2$ are simulated using standard normal distribution. We simulate various scenarios: the number of true alternative targets $M$ is 100 or 500 , and the number of acquirers $\mathrm{N}$ who make the choice is 30 or 100. Our sample has 29 deals (and hence 29 acquirers) and we randomly draw 9 alternative targets (besides the true chosen target) from a pool of 500-600 true alternative targets. So the simulation that best corresponds to our case is where the number of acquirers is 30 and the number of true alternative targets is 500 .

We first conduct conditional logit estimation on the full sample, and then we apply random sampling as described in the paper, with 9 randomly drawn alternative targets plus the true chosen target, and run a conditional logit estimation on the selected sample. We repeat this 
process 1000 times and report the results for both estimations in Table A1. As expected, the estimation with randomly selected sample has greater bias in parameter estimates and larger standard errors than the full sample estimation. However, the selected sample estimations use much less observations than full sample estimation. Taking this into account, the selected sample estimation does a reasonable job in recovering the true value. We can see in Table A1 that the true value falls within 2 standard errors of the parameter estimate almost all the time, and within 1 standard error of the parameter estimate most of the time. We also conduct t-tests between the parameter estimates in the two samples and fail to reject the null hypothesis that the two parameter estimates are equal. Therefore, the simulation study supplements the theoretical proof by Train (2005) and supports the use of the random sampling logit method for our sample size.

Table A1: Simulation for Logit with Random Sampling Method

\begin{tabular}{|c|c|c|c|c|c|c|c|c|c|c|c|}
\hline \multirow[b]{2}{*}{$\begin{array}{c}\begin{array}{c}\text { Number } \\
\text { of } \\
\text { Acquirers } \\
\mathbf{N}\end{array} \\
\text { A }\end{array}$} & \multirow[b]{2}{*}{$\begin{array}{c}\text { Number of } \\
\text { True } \\
\text { Alternative } \\
\text { Targets } \\
\text { M }\end{array}$} & \multirow[b]{2}{*}{$\begin{array}{l}\text { True } \\
\text { Value }\end{array}$} & \multicolumn{4}{|c|}{ Full Sample } & \multirow[b]{2}{*}{$\begin{array}{c}\text { T-test on } \\
\text { two } \\
\text { sample } \\
\text { estimate }^{\mathrm{b}}\end{array}$} & \multicolumn{4}{|c|}{ Randomly Selected Sample of 10 alternate targtes } \\
\hline & & & $\begin{array}{l}\text { Parameter } \\
\text { Estimates }^{\mathrm{a}}\end{array}$ & $\begin{array}{c}\text { Standard } \\
\text { Error }^{\mathrm{a}}\end{array}$ & $\begin{array}{c}\text { True } \\
\text { Value } \\
\text { lies } \\
\text { within 1 } \\
\text { StdErr }\end{array}$ & $\begin{array}{c}\text { True } \\
\text { Value } \\
\text { lies } \\
\text { within } 2 \\
\text { StdErr }\end{array}$ & & $\begin{array}{l}\text { Parameter } \\
\text { Estimates }^{\mathrm{a}}\end{array}$ & $\begin{array}{c}\text { Standard } \\
\text { Error }^{\mathrm{a}}\end{array}$ & $\begin{array}{c}\text { True } \\
\text { Value } \\
\text { lies } \\
\text { within 1 } \\
\text { StdErr }\end{array}$ & $\begin{array}{c}\text { True } \\
\text { Value lies } \\
\text { within } 2 \\
\text { StdErr } \\
\end{array}$ \\
\hline \multirow[t]{4}{*}{30} & 100 & 1 & $1.02^{c}$ & $0.26^{c}$ & $69 \%$ & $95 \%$ & 0.90 & 1.15 & 0.39 & $87 \%$ & $100 \%$ \\
\hline & & 2 & $2.05^{c}$ & $0.29^{c}$ & $68 \%$ & $95 \%$ & 0.90 & 1.93 & 0.39 & $92 \%$ & $100 \%$ \\
\hline & 500 & 1 & $1.01^{c}$ & $0.21^{\mathrm{c}}$ & $68 \%$ & $96 \%$ & 0.92 & 1.11 & 0.34 & $86 \%$ & $100 \%$ \\
\hline & & 2 & $2.02^{c}$ & $0.23^{c}$ & $69 \%$ & $96 \%$ & 0.87 & 2.19 & 0.52 & $89 \%$ & $100 \%$ \\
\hline \multirow[t]{4}{*}{100} & 100 & 1 & 1.01 & 0.14 & $70 \%$ & $96 \%$ & 0.96 & 1.06 & 0.33 & $89 \%$ & $100 \%$ \\
\hline & & 2 & 2.02 & 0.16 & $70 \%$ & $97 \%$ & 0.82 & 2.25 & 0.38 & $73 \%$ & $100 \%$ \\
\hline & 500 & 1 & 1.00 & 0.12 & $68 \%$ & $96 \%$ & 0.84 & 1.21 & 0.24 & $60 \%$ & $98 \%$ \\
\hline & & 2 & 2.00 & 0.13 & $67 \%$ & $96 \%$ & 0.86 & 2.18 & 0.26 & $70 \%$ & $98 \%$ \\
\hline
\end{tabular}

Notes:

${ }^{a}$ The reported values here are means of estimation results from 1000 repetitions.

b. The t-test was conducted on two sets of parameter estimates of 1000 each from full and randomly selected sample.

c. One estimation result is removed, because it has standard error $>600$. 


\section{Appendix B: Illustration for the Calculation of Intensification and Expansion Factors}

Assume that the therapy class structure is as given in Figure B1. Assume further that the therapy classes to which acquirer's and target's pipeline and approved drugs belong and their corresponding market and R\&D scores are as given in Table B1.

Figure B1: Example of Therapy Class Structure

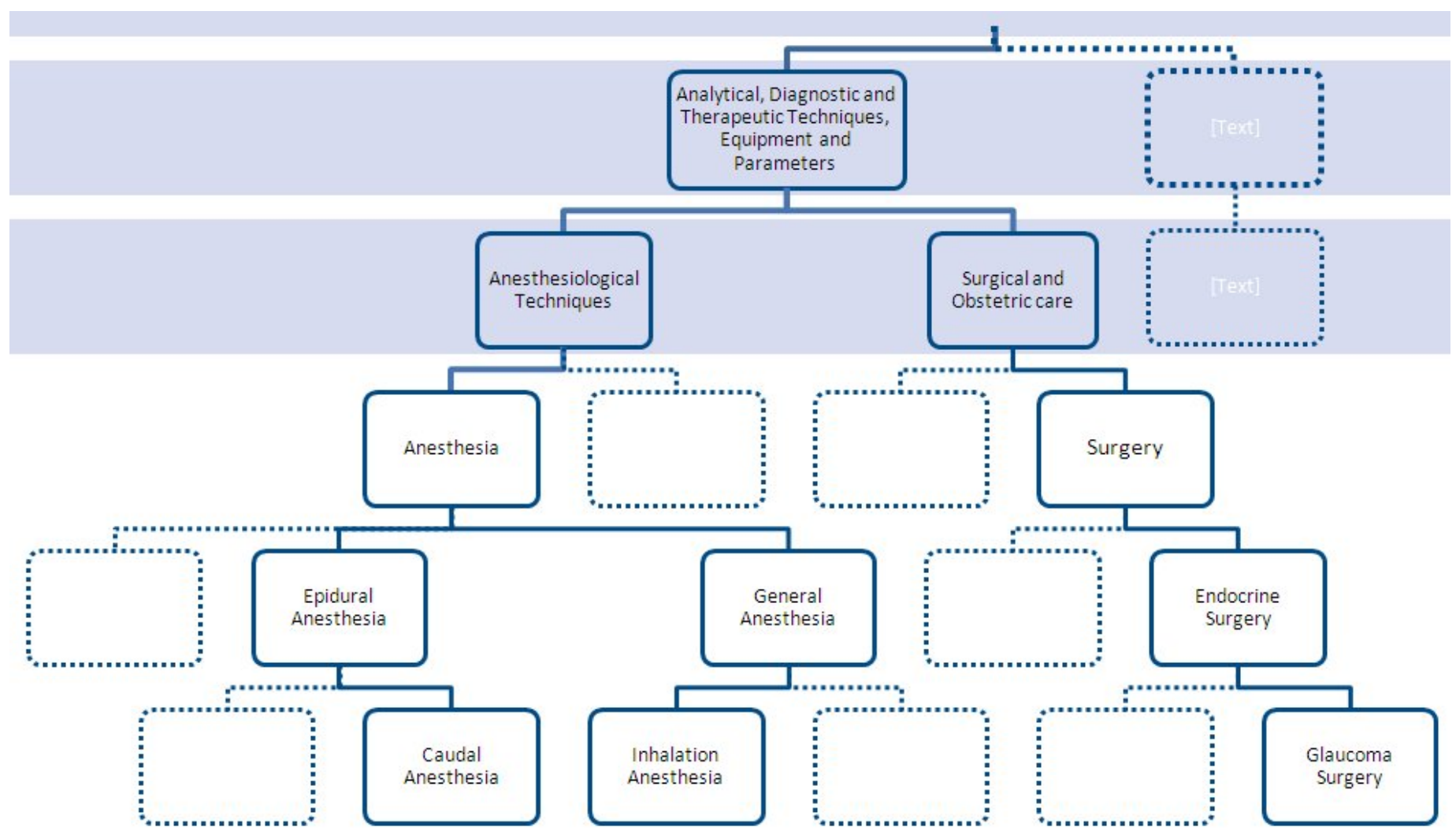

Table B1: Example for coding representation of therapeutic classes from Figure B1

\begin{tabular}{|c|c|c|}
\hline Therapy class & Market Score & R\&D Score \\
\hline \multicolumn{3}{|c|}{ Panel I: Acquirer } \\
\hline glaucoma surgery & 2 & 0.07095 \\
\hline caudal anesthesia & 0 & 0.9 \\
\hline \multicolumn{2}{|c|}{ Panel II: Target } \\
\hline glaucoma surgery & 1 & 0.215 \\
\hline endocrine surgery & 0 & 0.685 \\
\hline inhalation anesthesia & 0 & 0.07095 \\
\hline
\end{tabular}


In Table B1, the acquirer's market score of 2 for glaucoma surgery may arise because the acquirer has two approved drugs (each with a weight of 1) in this therapy class. Likewise, the acquirer's R\&D score of 0.0795 for glaucoma surgery may arise because it has one drug is in the pre-clinical phase (with its clinical approval probability of 0.0795).

The similarity factors between therapy classes with acquirer's pipeline drugs and therapy classes with target's pipeline drugs are calculated in Table B2. The R\&D intensification factor is 1.06323 , the sum of similarity factors for.each of the therapy class combinations in Table B2.

Table B2: Example for calculation of $R \& D$ intensification factors

\begin{tabular}{|c|c|c|}
\hline Therapy classes & \multicolumn{2}{|c|}{ Therapy classes with acquirer pipeline drugs } \\
\cline { 2 - 3 } with target & glaucoma surgery & caudal anesthesia \\
\hline glaucoma & $\left(1 / 2^{0}\right) *(0.07095+0.215)=0.28595$ & $0^{*}(0.9+0.215)=0$ \\
\hline endocrine & $\left(1 / 2^{0.5}\right) *(0.07095+0.685)=0.5345$ & $0^{*}(0.9+0.685)=0$ \\
\hline inhalation & $0^{*}(0.07095+0.07095)=0$ & $\left(1 / 2^{2}\right) *(0.9+0.07095)=0.2427$ \\
\hline
\end{tabular}

The similarity factors between therapy classes with acquirer's approved drugs and therapy classes with target's approved drugs are calculated in Table B3. The market intensification factor is 3 , the sum of similarity factors for.each of the therapy class combinations in Table B3.

Table B3: Example for calculation of market intensification factor

\begin{tabular}{|c|c|}
\hline Therapy classes with & Therapy classes with acquirer approved drugs \\
\cline { 2 - 2 } target approved drugs & glaucoma surgery \\
\hline glaucoma surgery & $\left(1 / 2^{0}\right)^{*}(2+1)=3$ \\
\hline
\end{tabular}

The similarity factors between therapy classes with acquirer's approved drugs and therapy classes with target's pipeline drugs are calculated in Table B4. The Market to $R \& D$ intensification factor is 4.1136 , the sum of similarity factors for each of the therapy class combinations in Table B4.

The similarity factors between therapy classes with acquirer's pipeline drugs and therapy classes with target's approved drugs are calculated in Table B5. The $R \& D$ to Market 
intensification factor is 1.0795 , the sum of similarity factors for.each of the therapy class combinations in Table B5.

Table B4: Example for calculation of Market to R\&D Intensification factor

\begin{tabular}{|c|c|}
\hline \multirow{2}{*}{$\begin{array}{c}\text { Therapy classes with } \\
\text { target pipeline drugs }\end{array}$} & Therapy classes with acquirer approved drugs \\
\cline { 2 - 2 } & glaucoma surgery \\
\hline glaucoma surgery & $\left(1 / 2^{0}\right)^{*}(2+0.215)=2.215$ \\
\hline endocrine surgery & $\left(1 / 2^{0.5} *(2+0.685)=1.8985\right.$ \\
\hline inhalation anesthesia & $0^{*}(2+0.07095)=0$ \\
\hline
\end{tabular}

Table B5: Example for calculation of R\&D to Market Intensification factor

\begin{tabular}{|c|c|c|}
\hline Therapy classes with & \multicolumn{2}{|c|}{ Therapy classes with acquirer pipeline drugs } \\
\cline { 2 - 3 } target approved drugs & glaucoma surgery & caudal anesthesia \\
\hline glaucoma surgery & $\left(1 / 2^{0}\right) *(0.0795+1)=0.0795$ & $0 *(0.9+1)=0$ \\
\hline
\end{tabular}

The complementarity factors for therapy classes with target's pipeline drugs are calculated in Table B6. The $R \& D$ expansion factor is 0.2422 , the sum of complementarity factors for.each of the target therapy classes in Table B6.

Table B6: Example for calculation of R\&D expansion factor

\begin{tabular}{|c|c|}
\hline $\begin{array}{c}\text { Therapy classes with } \\
\text { target pipeline drugs }\end{array}$ & Complementarity Factors \\
\hline glaucoma surgery & $0.5 * 0 * 0.215=0$ \\
\hline endocrine surgery & $0.5^{*} 0.5 * 0.685=0.1712$ \\
\hline inhalation anesthesia & $0.5 * 2 * 0.07095=0.07095$ \\
\hline
\end{tabular}

The complementarity factors for therapy classes with target's approved drugs are calculated in Table B7. The market expansion factor is 0 , the sum of complementarity factors for.each of the target therapy classes in Table B7.

Table B7: Example for calculation of R\&D expansion factor

\begin{tabular}{|c|c|}
\hline $\begin{array}{c}\text { Therapy classes with } \\
\text { target approved drugs }\end{array}$ & Complementarity Factors \\
\hline glaucoma surgery & $0.5^{*} 0 * 1=0$ \\
\hline
\end{tabular}




\section{Web Appendix A: RESEARCH FINDINGS ON INTERFIRM SIM ILARITY VERSUS COM PLEM ENTARITY IN A M ERGER CONTEXT (continue on next pagé)}

Adapted from Swaminathan, M urshed and Hulland (2008)

\begin{tabular}{|c|c|c|c|c|c|c|c|}
\hline Authors & $\begin{array}{l}\text { Dependent } \\
\text { Variable }\end{array}$ & Independent Variables & $\begin{array}{l}\text { similarity/ complementarity in } \\
\text { Market between acquirer and } \\
\text { target firm }\end{array}$ & $\begin{array}{l}\text { similarity/complem } \\
\text { entarity in } R \& D \\
\text { between acquirer } \\
\text { and target firm }\end{array}$ & $\begin{array}{l}\text { market and } \\
\text { R\&D } \\
\text { interactions } \\
\text { between } \\
\text { acquirer and } \\
\text { target firm }\end{array}$ & Empirical Context & Findings \\
\hline $\begin{array}{l}\text { Singh and } \\
\text { Montgomer } \\
\text { y (1987) }\end{array}$ & $\begin{array}{l}\text { stock market } \\
\text { returns }\end{array}$ & $\begin{array}{l}\text { relatedness between } \\
\text { acquirer and target }\end{array}$ & $\begin{array}{l}\text { presence (versus absence) of } \\
\text { similar product-markets }\end{array}$ & $\begin{array}{l}\text { presence (versus } \\
\text { absence) of similar } \\
\text { technologies }\end{array}$ & none & $\begin{array}{l}105 \text { mergers } \\
\text { announced in the } \\
1975-1980 \text { period }\end{array}$ & $\begin{array}{l}\text { Greater dollar gains found when } \\
\text { the merging firms are related } \\
\text { (versus unrelated). }\end{array}$ \\
\hline $\begin{array}{l}\text { Shelton } \\
\text { (1988) }\end{array}$ & returns & $\begin{array}{l}\text { product-market fit } \\
\text { between acquirer and } \\
\text { target }\end{array}$ & same as above & same as above & none & $\begin{array}{l}218 \text { mergers } \\
\text { announced in the } \\
1962-1983 \text { period }\end{array}$ & $\begin{array}{l}\text { Related acquisitions create the } \\
\text { greatest value }\end{array}$ \\
\hline $\begin{array}{l}\text { Datta, } \\
\text { Pinches, and } \\
\text { Narayanan } \\
(1992) \\
\end{array}$ & $\begin{array}{l}\text { wealth } \\
\text { effects }\end{array}$ & $\begin{array}{l}\text { number of bids, bidder's } \\
\text { approach, type of } \\
\text { financing, type of } \\
\text { acquisition }\end{array}$ & same as above & same as above & none & $\begin{array}{l}\text { M eta-analysis of } \\
41 \text { studies of } \\
\text { mergers }\end{array}$ & $\begin{array}{l}\text { Significant gains to acquirers in } \\
\text { related (similar) acquisitions }\end{array}$ \\
\hline $\begin{array}{l}\text { Harrison et } \\
\text { al.(1991) }\end{array}$ & $\begin{array}{l}\text { accounting } \\
\text { gains }\end{array}$ & $\begin{array}{l}\text { similarity in research and } \\
\text { development }(R \& D) \text {, } \\
\text { capital, and administrative } \\
\text { intensities across acquirers } \\
\text { and targets }\end{array}$ & no specific measurement & $\begin{array}{l}\text { Absolute difference } \\
\text { between acquirer } \\
\text { and target } R \& D \\
\text { intensities(R\&D } \\
\text { spending divided by } \\
\text { total revenues) } \\
\end{array}$ & none & $\begin{array}{l}\text { Sample size } \\
\text { ranged from } 198 \\
\text { to } 441 \text { for } \\
\text { different types of } \\
\text { complementaritie } \\
\text { s tested }\end{array}$ & $\begin{array}{l}\text { Significant gains from } \\
\text { complementarity. The effect of } \\
\text { R\&D complementarity was } \\
\text { greater in unrelated } \\
\text { acquisitions. }\end{array}$ \\
\hline $\begin{array}{l}\text { Ramaswamy } \\
\text { (1997) }\end{array}$ & $\begin{array}{l}\text { accounting } \\
\text { gains }\end{array}$ & $\begin{array}{l}\text { similarity between } \\
\text { acquirers and targets on } \\
\text { five strategic variables (i.e., } \\
\text { market coverage, } \\
\text { operational efficiency, } \\
\text { marketing activity, client } \\
\text { mix, and risk propensity) } \\
\end{array}$ & $\begin{array}{l}\text { A distance metric was used to } \\
\text { compute the difference } \\
\text { between acquirers and targets } \\
\text { on market coverage, operational } \\
\text { efficiency, marketing activity } \\
\text { and client mix }\end{array}$ & no measurement & none & $\begin{array}{l}\text { Sample of } 46 \\
\text { horizontal } \\
\text { mergers in the } \\
\text { banking industry }\end{array}$ & $\begin{array}{l}\text { Differences had a large negative } \\
\text { impact on performance in } \\
\text { horizontal mergers in the } \\
\text { banking industry context }\end{array}$ \\
\hline $\begin{array}{l}\text { Hitt et al. } \\
\text { (1998) }\end{array}$ & $\begin{array}{l}\text { accounting } \\
\text { gains }\end{array}$ & $\begin{array}{l}\text { product-market } \\
\text { relatedness and resource } \\
\text { complementarities }\end{array}$ & $\begin{array}{l}\text { Qualitative presence of related } \\
\text { resources or assets (e.g., Quaker } \\
\text { Oats' acquisition of pet food } \\
\text { brands to complete its own pet } \\
\text { food offerings). }\end{array}$ & $\begin{array}{l}\text { Possibly was } \\
\text { considered in the } \\
\text { related assets }\end{array}$ & none & $\begin{array}{l}\text { Case studies } \\
\text { involving } 24 \\
\text { mergers }\end{array}$ & $\begin{array}{l}\text { Resource complementarities } \\
\text { explained success }\end{array}$ \\
\hline $\begin{array}{l}\text { Larsson and } \\
\text { Finkelstein } \\
\text { (1999) }\end{array}$ & $\begin{array}{l}\text { synergy } \\
\text { realization }\end{array}$ & $\begin{array}{l}\text { combination potential, the } \\
\text { degree of integration } \\
\text { achieved, and the lack of } \\
\text { employee resistance }\end{array}$ & $\begin{array}{l}\text { similarity and complementary } \\
\text { (on a } 5 \text { point scale) of marketing } \\
\text { operations (e.g., geographic } \\
\text { markets, customer groups, and } \\
\text { industries); similarity and } \\
\text { complementary of product } \\
\text { operations (e.g. types of input, } \\
\text { process, and product) }\end{array}$ & no measurement & none & $\begin{array}{l}\text { Case studies of } \\
112 \text { mergers }\end{array}$ & $\begin{array}{l}\text { Complementary operations } \\
\text { boosted synergy realization, } \\
\text { particularly when organizational } \\
\text { integration was present }\end{array}$ \\
\hline
\end{tabular}


Web Appendix B: RESEARCH FINDINGS ON INTERFIRM SIMILARITY VERSUS COM PLEM ENTARITY IN A M ERGER CONTEXT (continuęd)

Adapted from Swaminathan, M urshed and Hulland (2008)

\begin{tabular}{|c|c|c|c|c|c|c|c|}
\hline Authors & $\begin{array}{l}\text { Dependent } \\
\text { Variable }\end{array}$ & Independent Variables & $\begin{array}{l}\text { similarity/ complementarity in } \\
\text { Market between acquirer and } \\
\text { target firm }\end{array}$ & $\begin{array}{l}\text { similarity/ complementa } \\
\text { rity in R\&D between } \\
\text { acquirer and target firm }\end{array}$ & $\begin{array}{l}\text { market and R\&D } \\
\text { interactions } \\
\text { between acquirer } \\
\text { and target firm } \\
\end{array}$ & $\begin{array}{l}\text { Empirical } \\
\text { Context }\end{array}$ & Findings \\
\hline $\begin{array}{l}\text { Swaminathan, } \\
\text { Murshed and } \\
\text { Hulland (2008) }\end{array}$ & $\begin{array}{l}\text { stock market } \\
\text { returns }\end{array}$ & $\begin{array}{l}\text { Strategic emphasis difference, } \\
\text { consolidation motive, unrelated } \\
\text { diversification motive, acquirer } \\
\text { strategic emphasis (marketing or } \\
R \& D \text { ), acquirer marketing resources, } \\
\text { relative size, industry dummies }\end{array}$ & \multicolumn{2}{|c|}{$\begin{array}{l}\text { Strategic emphasis alignment is defined as the absolute } \\
\text { difference between the acquirer and target strategic } \\
\text { emphasis measure, which is [(advertising expenditures - } \\
\text { R\&D expenditures)/ total assets of the firm] }\end{array}$} & $\begin{array}{l}2 \\
\text { d } \\
\text { M } \\
\text { th } \\
\text { in } \\
\text { e } \\
\text { cl } \\
\text { fc }\end{array}$ & $\begin{array}{l}206 \text { publicly } \\
\text { disclosed } \\
\text { M\&As across } \\
\text { three } \\
\text { industries: } \\
\text { electronics, } \\
\text { chemicals, and } \\
\text { foods. }\end{array}$ & $\begin{array}{l}\text { When merging firms have } \\
\text { low strategic emphasis } \\
\text { alignment, value is } \\
\text { enhanced when the merger } \\
\text { motive is diversification; } \\
\text { when merging firms have } \\
\text { high strategic emphasis } \\
\text { alignment, value is } \\
\text { enhanced when the merger } \\
\text { motive is consolidation. }\end{array}$ \\
\hline $\begin{array}{l}\text { Prabhu, } \\
\text { Chandy, Ellis } \\
\text { (2005) }\end{array}$ & $\begin{array}{l}\text { Acquirer's } \\
\text { product } \\
\text { innovation }\end{array}$ & $\begin{array}{l}\text { Acquirer's breath and depth of } \\
\text { knowledge (and their interaction } \\
\text { with acquisition), knowledge } \\
\text { similarities between acquirer and } \\
\text { target (and its square), R\&D intensity } \\
\text { (R\&D expenditure/sales), acquirer } \\
\text { parent company size, biotech } \\
\text { dummy, target level of technical } \\
\text { knowledge, target value, target being } \\
\text { non-pharmaceutical firms, target } \\
\text { being foreign }\end{array}$ & no measurements & $\begin{array}{l}\text { similarity is measured by } \\
\text { the number of patent } \\
\text { subclasses shared by the } \\
\text { acquirer and target firm, } \\
\text { divided by the total } \\
\text { number of patent classes } \\
\text { owned by the acquirer } \\
\text { and target combined }\end{array}$ & $\begin{array}{l}35 \\
\text { ac } \\
\text { be } \\
\text { an } \\
\text { ph } \\
\text { inc }\end{array}$ & $\begin{array}{l}35 \text { public } \\
\text { acquirers } \\
\text { between } 1988 \\
\text { and } 1997 \text { in } \\
\text { pharmaceutical } \\
\text { industry }\end{array}$ & $\begin{array}{l}\text { Acquisition can help } \\
\text { innovation, and its positive } \\
\text { effect increase with } \\
\text { acquirer's breadth and } \\
\text { depth of knowledge; the } \\
\text { increase in similarity } \\
\text { between acquirer and target } \\
\text { knowledge first improves } \\
\text { innovation, after certain } \\
\text { point it becomes } \\
\text { detrimental to innovation. }\end{array}$ \\
\hline $\begin{array}{l}\text { Sorescu, } \\
\text { Chandy and } \\
\text { Prabhu (2007) }\end{array}$ & $\begin{array}{l}\text { Acquirer's long } \\
\text { term stock } \\
\text { performance, } \\
\text { Selection } \\
\text { (Target quality), } \\
\text { Deployment (of } \\
\text { the target top } \\
\text { scientists) }\end{array}$ & $\begin{array}{l}\text { Product support, product } \\
\text { development, selection, deployment, } \\
\text { target size, acquirer assets, relative } \\
\text { size (acquirer/target), relatedness, } \\
\text { transaction lag (days), unanticipated } \\
\text { ROA (\%) }\end{array}$ & $\begin{array}{l}\text { Relatedness measured as SIC } \\
\text { match }\end{array}$ & none & $\begin{array}{l}2 \\
a \\
b \\
a \\
p \\
\text { in }\end{array}$ & $\begin{array}{l}238 \text { public } \\
\text { acquirers } \\
\text { between } 1992 \\
\text { and } 2002 \text { in } \\
\text { pharmaceutical } \\
\text { industry }\end{array}$ & $\begin{array}{l}\text { Firms with high product } \\
\text { capital (i.e., those with } \\
\text { greater product } \\
\text { development and support } \\
\text { assets) make superior } \\
\text { selection and deployment of } \\
\text { targets' innovation } \\
\text { potential. }\end{array}$ \\
\hline This paper & Target selection & $\begin{array}{l}\text { Target firms' financial indicators (sales, } \\
\text { return on assets, debt to assets ratio), } \\
\text { potential market intensification and } \\
\text { expansion factors, potential pipeline } \\
\text { intensification and expansion factors, } \\
\text { and interaction between market and } \\
\text { pipeline factors }\end{array}$ & $\begin{array}{l}\text { Intensification factor is defined } \\
\text { as overlapping between } \\
\text { acquirer and target firms' } \\
\text { approved drugs, Expansion } \\
\text { factor is defined as the } \\
\text { additional drugs target firm can } \\
\text { bring to acquirer firm }\end{array}$ & $\begin{array}{l}\text { Intensification factor is } \\
\text { defined as overlapping } \\
\text { between acquirer and } \\
\text { target firms' pipeline } \\
\text { projects, Expansion factor } \\
\text { is defined as the } \\
\text { additional pipeline } \\
\text { projects target firm can } \\
\text { bring to acquirer firm }\end{array}$ & $\begin{array}{l}\text { Market to pipeline is } \\
\text { defined as } \\
\text { overlapping } \\
\text { between acquirer's } \\
\text { approved product } \\
\text { and potential target } \\
\text { firms' pipeline } \\
\text { projects, Pipeline to } \\
\text { market is similarly } \\
\text { defined }\end{array}$ & $\begin{array}{l}\text { is } 29 \text { public } \\
\text { acquisitions } \\
\text { between } \\
2002 \text { and } \\
2008 \text { in } \\
\text { pharmaceuti } \\
\text { cal industry } \\
\text { to }\end{array}$ & $\begin{array}{l}\text { Acquirer firms avoid choosing } \\
\text { targets that have very similar } \\
\text { products or pipeline as } \\
\text { themselves, instead, they } \\
\text { choose target with similar } \\
\text { products as their pipeline, or } \\
\text { target with pipeline similar to } \\
\text { their current products. }\end{array}$ \\
\hline
\end{tabular}

The reference for Web Appendix $\mathrm{A}$ is included in the main paper 


\section{Web Appendix B: Various Theories in Merger and Acquisition}

Merger and acquisition is a topic that attracts wide attention from fields such as economics, finance, organizational behavior and law. A thorough literature review on M\&A can be found in Parvinen (2003), which lists various theories regarding the explanations and justifications for M\&A. These schools of thoughts can be classified as follows: strategy theories; process theories; financial theories; governance theories and competence-related theories. Each school of thought contains several branches, which we introduce in the following paragraphs.

\section{Web-B1. The strategy theories}

According to Parvinen (2003), management theories are the first and foremost approach for acquisition. Developed in 1980s and 1990s, strategy paradigms include competitive strategy (Porter 1980, 1985,1996, Porter and Fuller 1986, Besanko et al. 1990) and resource-based strategy (whose antecedents include Penrose 1959, Rumelt 1974, Nelson and Winter 1982 and major contributions include Hamel and Prahalad 1990, 1996, Singh and Montgomery 1987, Teece 1982, Barney 1988, Rumelt, Schendel and Teece 1994).

Key acquisition related corporate strategy areas include efficiency gains, risk diversification, operating synergies, competitive realignment, competence, resources, information realignment, and redistributive realignment (Weston et al. 2001). The two most important acquisition related strategy themes are relatedness and synergy.

The relatedness of activities has received extensive and increasing attention in strategy literature, with the rise of the competence perspective to corporate strategy 
(Hamel and Prahalad 1990, 1994, Rumelt, Schendel and Teece 1994) and a more elaborate understanding of the need for strategic and organizational fit (Porter 1996). Already the earlier contributions in the spirit of the resource-based theory of the firm (Rumelt 1974, 1992, Bettis 1981, Nelson and Winter 1982) found that large firms with unrelated diversification (often as a result of acquisition activity) were outperformed by firms with related activities on the whole. Thus relatedness between activities, i.e. synergies arising from appropriate portfolio management, restructuring, sharing of activities and the transfer of resources (Porter 1987), is argued to be a driving force behind the successful co-existence between merged firms in certain industries such as pharmaceuticals.

The notion of synergy has derived from two particular intellectual orientations. The first is the theory of differential managerial efficiency (Teece 1987), which argues that acquisition gains are due to more efficient organizations and pooling of complementary resources (Gammelgaard 2001). The other relates to the replacement of inefficient management following acquisition, i.e. the operation of an allocation market for corporate control (Fama 1980, Manne 1965, Walsh 1988, 1989). More specifically, acquisition synergies have also been categorized into operational synergies ${ }^{1}$, collusive synergies ${ }^{2}$, managerial synergies ${ }^{3}$ and financial synergies according to their measurability and the ability to generate benefits (Weston et al 2001, Larsson and Finkelstein 1999). We developed the intensification and expansion

\footnotetext{
${ }^{1}$ Resulting from economies of scale for example in.production, R\&D, staff functions and marketing.

${ }^{2}$ Resulting from increased market power and bargaining power.

${ }^{3}$ Corresponding to the efficiencies from the market for corporate control
} 
factors as our synergy measures partially based on the relatedness of the acquirer's and target firm's product and research portfolios. Of course these measures are rough proxies for actual synergies, whose realization depends on other factors such as successful integration.

\section{Web-B2. Process theories:}

The process theories (Hunt 1990, Haspeslagh and Jemison 1991, Pablo 1994, Larsson and Finkelstein 1999), were spurred by the strategy school's inability to emphasize the significance of the acquisition process. The basic argument is that the acquisition process itself can be an important determinant of the various acquisition outcomes (Jemison and Sitkin 1986). As recognized by Puranam (200, p.6-7), one of the central tenets in the process approach is that the acquisition of the equity of another company does not automatically lead to the creation of necessary links between the resources of the merging companies. Costly transactions, most importantly the alignment of incentives, the creation of coordination mechanisms and the adjustment of information flows governing the use of the resources, are needed (Ranft 1997, Zollo 1998, Zollo and Singh 2000).

Before the rise of the process stream in the 1980s, the conventional acquisition literature argued for a sequential, one-process view of acquisition as illustrated in Figure Web-B1.

Figure Web-B1: Conventional View of the M\&A Process (Haspeslagh and Jemison 1991) 


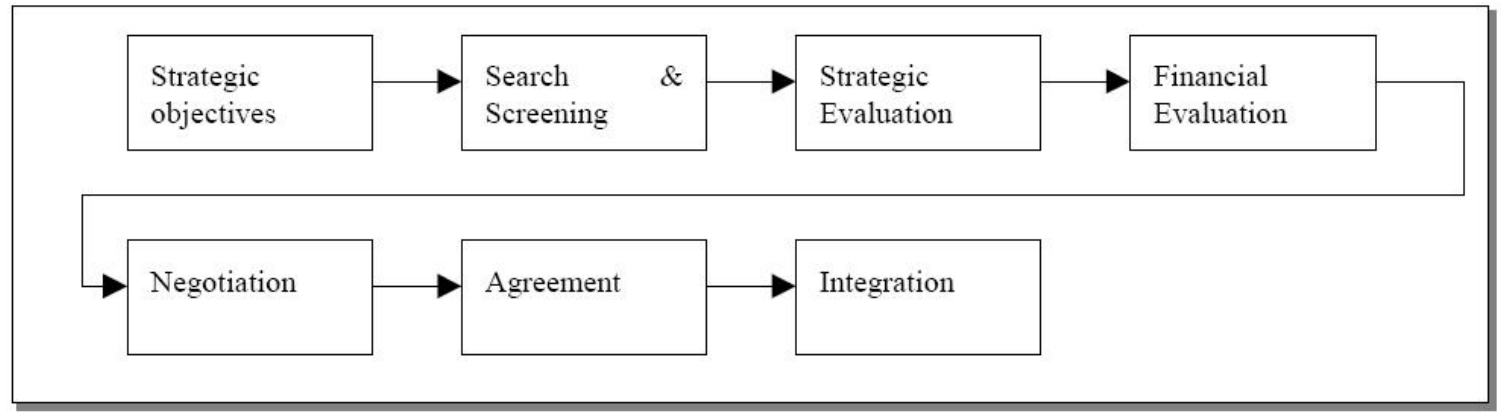

Proponents of the process stream of acquisition, however, argued that there are at least two different processes, namely the decision making process and the integration process (Haspeslagh and Jemison 1991, pp.12). Figure Web-B2 presents the process stream's views of the embeddings of the acquisition process in certain strategic and organizational fit and Figure Web-B3 presents a coarse division of acquisition process problems. Both of these views engulf the same sequential steps as in the conventional view on the acquisition process.

Figure Web-B2: The Process Streams' View of the Embeddedness of the M\&A Process in a Certain Strategic and Organizational Fit (Jemison and Sitkin 1986)

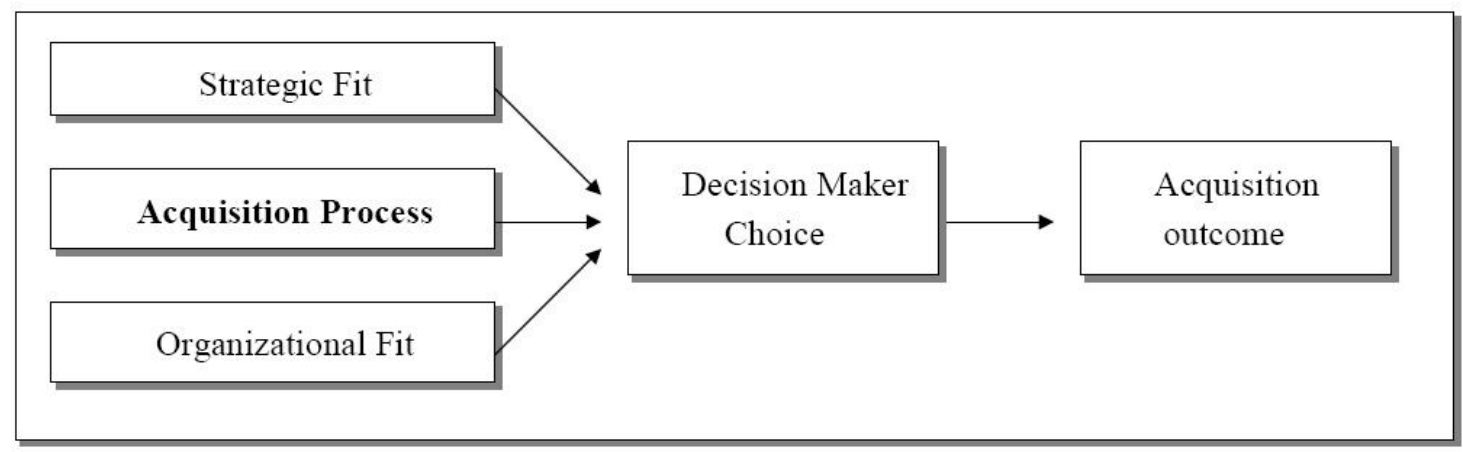

Figure Web-B3: The Process Streams' View of the Acquisition Process Problems (Haspeslagh and Jemison 1991) 


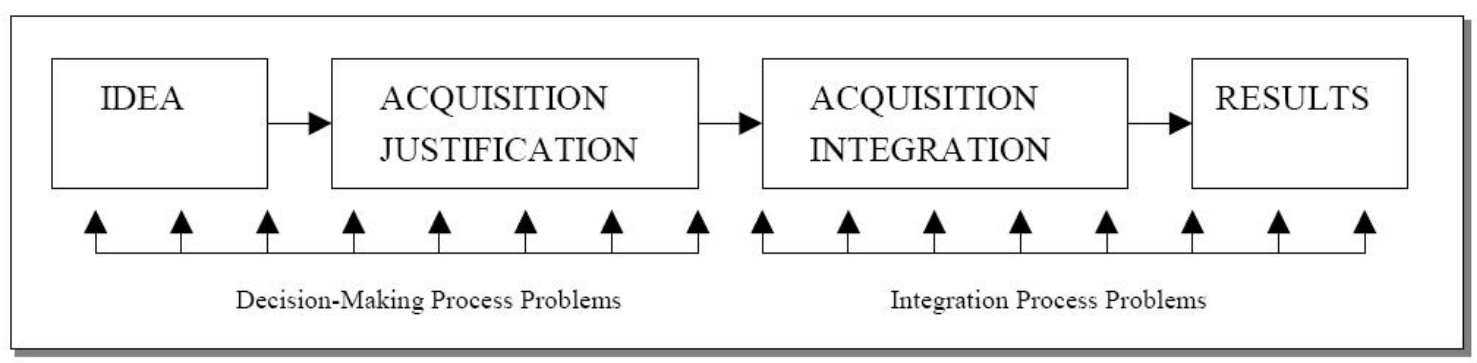

The process stream provides theoretical support for our empirical work. The process stream's emphasis on the acquisition process justifies our focus on the acquisition decision making process, which is the first half of the acquisition process. Although the emphasis of process theory is not always on target selection, we use its general idea by incorporating various consideration factors into the acquiring managers' choice model to fully reflect the simultaneity of the consideration.

\section{Web-B3 Financial theories:}

Financial theories include capital markets perspective, corporate finance perspective and valuation theory. The capital markets perspective employs capital market theory to analyze acquisition success, the role of globalizing capital markets in the formation of cross-border acquisitions, and the use of capital market instruments in performing as well as preventing acquisition transactions. The key source of financial synergy from acquisition are argued be a) reduced capital cost as internal financing is cheaper than external financing, b) the utilization of tax shield and c) the increase in the debt capacity of the merged company. In our research we do not emphasize the financial synergy as much as economic synergies. However, we include financial synergy terms in the balance model specification as a robustness check. 
Corporate finance literature develops agency theory and transaction cost economic theory which lie in the realm of institutional and organizational economics. Agency theory argues that problems arise in acquisition situations when managers' and owners' interests are not congruent (Holmstrom 1979, Fama 1980). This may result in non-value creating acquisitive behavior due to e.g. empire-building acquisitions (Roll 1986) and managerial risk reduction through diversifying acquisition (Amihud and Lev 1981). Managerial hubris and empire building have been attributed as the most important motivations behind acquisition behavior. Roll (1986) elevated hubris as an equally important motivation for acquisition as taxes, synergy and removing inefficient management. Hayward and Hambrick (1997) relate the amount of acquisition premiums paid to the extent of CEO hubris, and their findings imply that hubris might actually be a primary reason for acquisition pricerelated acquisition 'failures'.

In our analysis we only chose acquisition deals where both target and acquirer are in the same industry. Therefore, the diversification concerns are not relevant. Since a manager's motives are usually difficult to observe and quantify, we exclude the no-merger option and specify the choice model to be conditional on the merger decision having being made. This avoids agency problems such as empire building and managerial hubris because the manager's decision on whether or not to have a merger is not our concern. We only model the choice of target once the decision to acquire is determined. 
The valuation theory of acquisition suggests that acquiring firm's managers have better information about the target's value than the stock market which makes it profitable to buy the target at a low price and sell it in pieces or merge it into acquirer's business. Since we want to focus on mergers where the incentive is to generate economic synergies, we exclude deals with other incentives in the data collection process.

\section{$\underline{\text { Web-B4 Governance theories }}$}

Governance theories are many institutional and organizational theories related to governance of firm that are classified together by Parvinen (2003). These theories have shed important light on the acquisition question. The most prominent branches in this literature include the neoclassical firm-as-a-production function literature; the nexus of contracts view; the formal and positivist principal-agent theories; early incomplete contracting theory characterized by the coordination problem; property rights theory; and transaction cost economics. A road map of governance theory can be found below.

Neoclassical economics (Arrow 1951, 1962; Arrow and Debreu 1954; Debreu 1959 and Solow 1963) is not interested in acquisition at the firm level, but at the macroeconomic level. They noticed that mergers occur in waves (Bain 1944, Stigler 1950) and that they are vehicles of agglomeration, leading to monopoly concerns (Stigler 1951). The disturbance theory, which treats mergers as a macroeconomic phenomenon due to regulation changes or outside shocks to the economic environment (Trautwein ,1990), is consistent with the neoclassical perspective. When 
looking at the firm level, acquisition is considered a mere amalgamation of two production functions. Similarly, neoclassical economics sees the maximization of abnormal profit through monopoly power as the only justification for the existence of acquisition.

The main view of nexus of contracts perspective about acquisition is that actions and transactions involving firms are essentially similar to those on the market (Alchian and Desetz 1972; Jensen and Meckling 1976; Fama 1980 and Cheung 1983). It doesn't matter whether the contract between two companies is a mutually exclusive and exhaustive sales agreement, or a merger agreement.

The formal and positivist principal-agent theories include Hart and Holmström (1987), Ross (1973), Holmström (1979, 1982), Eisenhardt (1989); Jensen (1983, 1985); Fama and Jensen (1983); Jensen and Meckling (1992) and Harris and Raviv (1978). With the incentive arguments, the principal-agent framework has a lot of implications for acquisition at the level of the individual manager. We have discussed about these implications in the financial theories section.

The early discussions of incomplete contracting and coordination problem (Coase 1937; Simon 1945, 1951; Malmgren 1961) act as the basic foundations for the boundaries of the firm discussion. They introduce the key semantics and the central idea of incomplete contracting to the more recent transaction cost economics and property rights literature.

According to property rights literature ((Furubotn and Pejovich 1972; Hayek 1937, 1945; Coase 1960; Hart 1989, and Hart and Moore, 1990; Kreps 1990), 
acquisition is a vehicle for changing the ownership of a set of assets, thereby allocating (or attempting to allocate) the production resources in the hands of those who can use those assets most productively.

Transaction cost economics (Williamson 1971, 1975, 1977, 1985, 1986, 1991, 1996) has had significant influence over the development of acquisition theories. Transaction cost economics assumes that contracts can be incomplete and leads to hold-up problems. If the two parties in transaction want to avoid transaction cost, they can merge with each other and internalize the market transaction. Transaction cost theory has been applied to vertical and international acquisition cases (Klein, Crawford and Alchian, 1978). More specifically, the focus has been on synergistic efficiency considerations, and mergers have been analyzed with respect to their transaction cost economic properties (Richter 1999, p. 51-55). Richter's logic manifests how synergies between two separate businesses lower the transaction costs of using a factor of production (e.g. the same investor, the same external consulting services, the same distribution channel), thereby encouraging diversification into seemingly unrelated businesses. Similarly, potential benefits from diversification may arise if one business creates such positive externalities (e.g. a great motivation within a research department) that can be internalized by the other business in the form of productivity enhancing spillover effects.

These economic synergy arguments serve well as theoretical support for our model. From R\&D process to product manufacturing and sales, there are a lot of opportunities to utilize shared resources and enjoy the knowledge spillover effect if a 
diverse portfolio is maintained. We specifically measure such expansive synergy in our empirical testing.

\section{Web-B5 Competence theories}

Parallel to the governance perspective, the theory of the firm has also been enriched by theories known as the competence-(or, alternatively, resource-, capability-, or knowledge-) based views of the firm. In these theories, the conceptual focus is on the efficient use of bounded knowledge and on adapting to unanticipated change. They consist of the resource-based perspective of the firm (e.g. 'the resource dependence' view by Pfeffer and Salancik 1978; also Wernerfelt 1984; Dierickx and Coll 1989); the dynamic capabilities perspective (Nelson 1991; Teece, Pisano and Shuen 1997); the knowlege based theory of the firm (Kogut and Zander 1992; Nonaka and Takeuchi 1995); and the core competencies approach (Hamel and Prahalad 1990; Sanchez and Heene 1997). A map of the competence theories can be found in next page.

The main messages of this school of thoughts are:

- Firms exist because they produce and utilize knowledge, particularly tacit knowledge, more efficiently than markets (Kogut and Zander 1992).

- Moreover, a routine is thought of as 'the skill of an organization'. Capabilities (competencies, dynamic capabilities, higher-order organizing principles) are metaroutines that represent a firm's capacity to sustain a coordinated deployment of routines in its business operations (Foss and Foss 2000). 
- The boundaries of the firm are determined by knowledge-based considerations, not by mere contracting related to the solving of various incentive conflicts.

Knowledge assets that are non-contestable and idiosyncratic are usually governed within the firm, whereas complementary but dissimilar knowledge assets are best obtained through an inter-firm cooperative arrangement. (Foss and Foss 2000). - Firms' internal organization is best understood as a matter of creating a shared context (e.g. in terms of organizational culture) that can help in integrating and utilizing essentially local knowledge to build and leverage core competencies (Foss and Foss 2000; Sanchez and Heene 1997).

The competence view provides a clear definition of boundaries of firm and therefore provided solid foundation for justification of M\&A. The most conspicuous is the 'synergy' explanation for M\&A, which essentially states that relatedness between firms is the key to M\&A success (Lubatkin 1983, Singh and Montgomery 1987, Chatterjee 1986). Similarly, the role of M\&A in acquiring otherwise hard-to-get inimitable and distinctive resources and competencies has been acknowledged. The knowledge-based theory has been used by many M\&A researchers as the foundation for R\&D motivated acquisition (Prabhu, Chandy, Ellis 2005). A distinctive stream of literature has concentrated on the transfer and acquisition of unique technologies through M\&A (Hagedoorn 1990, Hagedoorn and Sadwski 1999, Laamanen and Autio 1996, Laamanen 1997). Organizational learning through M\&A (Kusewitt 1985, Zollo and Singh 2000, Haleblian and Finkelstein 1999) and M\&A in technological and organizational innovation (Kabiraj and Mukherjee 2000) are related explanations. 
Many of these justifications for the existence of M\&A rely on and emphasize the role of tacit knowledge in value creation.

Given the importance of knowledge in a firm and the role M\&A can play in transferring knowledge across firms, we design specific variables to measure the amount and quality of knowledge of a potential target firm and how it fits into or extends the acquirer firm's existing knowledge. These measures help us test the firm's emphasis on knowledge and strategic fit.

The literature review above shows an interesting phenomenon: many schools of theories overlap and cross-fertilize each other. For instance, agency theory bellows to corporate finance and governance theory, resource-based view is referred to in both strategy and competence theory. Many of the theories are originated from the same school of thoughts and found applications in many different disciplines. This review therefore only serves as a rough road map of theories related to acquisition, rather than bullet-proof standard of classification. Due to space limitation, many theories that are not so relevant to our research are not detailed above, such as law and human resources literature. For more information on these theories, more specific reviews should be referred to.

\section{References for Web Appendix B:}

Alchian, A.A. and H. Demsetz. (1972), "Production, information costs and economic organization," American Economic Review 62 (5): 772-795.

Amihud, Y. and B. Lev. (1981), "Risk reduction as a managerial motive for conglomerate mergers: a transaction cost analysis," Bell Journal of Economics 12: 605-616. 
Arrow, K. (1951) Social Choice and Individual Values. New York: Wiley.

Arrow, K. (1962) Studies in Applied Probability and Management Science. New York: Wiley

Arrow, K. and G. Debreu. (1954), "Existence of an equilibrium for a competitive economy," Econometrica 22: 265-290.

Bain, J. (1944), "Industrial concentration and government anti-trust policy. In Williamson," H.F.(ed.). The Growth of the American Economy. New York: Prentice-Hall. pp. 616630.

Barney, J. (1988), "Returns to bidding firms in mergers and acquisitions: reconsidering the relatedness hypothesis," Strategic Management Journal 9, Special Issue: 71-78.

Besanko, D, M.K. Perry and R. Spady (1990), "The logit model of monopolistic competition: brand diversity," Journal of Industrial Economics 38(4): 397-416.

Cheung, S.S.N. (1983), "The contractual nature of the firm," Journal of Law and Economics 26:1-22.

Coase, R.H. (1937), "The nature of the firm," Economica 4: 386-405.

Coase, R.H. (1960), "The problem of social cost," Journal of Law and Economics 3: 1-44.

Debreu, G. (1959), Theory of Value: An Axiomatic Analysis of Economic Equilibrium. New York: Wiley.

Eisenhardt, K.M. (1989), "Agency theory: an assessment and review," Academy of Management Review 14: 57-74.

Fama, E. \& M. Jensen. (1983), "Agency problems and residual claims," Journal of Law and Economics 26: 327-49.

Fama, E. (1980), "Agency problems and the theory of the firm," Journal of Political Economy 88: 288-307.

Furubotn, E.G. \& S. Pejovich (1972), "Property rights and economic theory: a survey of recent literature," Journal of Economic Literature 10 (4): 1137-1162.

Gammelgaard, Jens, (2001), "Time and Path Dependencies in Foreign Acquisition Behaviours The History of Danish Takeovers Abroad 1888 to 1993," Working Papers, Copenhagen Business School, Department of International Economics and Management.

Hamel, G. \& C.K. Prahalad, (1990), "The core competence of the corporation," Harvard Business Review (May-June): 79-91. 
Hamel, G. \& C.K. Prahalad, (1994), Competing for the Future. Boston, Mass.: Harvard Business School Press.

Harris, M. \& A. Raviv (1978), "Some results on incentive contracts with application to education and employment, health insurance, and law enforcement," American Economic Review 68: 20-30.

Hart, O. \& B. Holmström (1987), "The theory of contracts," In Truman, F.B. Advances in Economic Theory: Fifth World Congress. Cambridge: Cambridge University Press pp. $71-155$

Hart, O. \& J. Moore (1990), "Property rights and the nature of the firm," Journal of Political Economy 98: 1119-1158.

Hart, O. (1989), "An economist's perspective on the theory of the firm," Columbia Law Review 89 (7): 1757-1774.

Haspeslagh, Philippe and David Jemison (1991), Managing Acquisitions, New York: Free Press.

Hayek, F. A. (1937), "Economics and knowledge," Economica N.S. 4: 33-54.

Hayek, F.A.(1945), "The use of knowledge in society," American Economic Review 35 (September): 519-30. Reprinted in Hayek, F.A. (1948) Individualism and Economic Order. Chicago: University of Chicago Press. pp. 77-91.

Hayward, M.L.A. \& D.C. Hambrick (1997), "Explaining premiums paid for large acquisitions:evidence of CEO hubris," Administrative Science Quarterly 42: 103-127.

Holmström, B. (1979), "Moral hazard and observability," Bell Journal of Economics 10: 74-91.

Holmström, B. (1982), "Moral hazard in teams," Bell Journal of Economics 13: 342-340.

Jemison, D.B. \& S.B. Sitkin (1986), "Corporate Acquisitions: A Process Perspective," Academy of Management Review 11(1): 145-163.

Jensen, M.C. \& W. Meckling (1976), "The theory of the firm: managerial behaviour, agency costs and ownership structure," Journal of Financial Economics 3: 305-360.

Jensen, M.C. \& W. Meckling (1992), "Specific and general knowledge, and organisational structure," In Werin, Lars \& Hans Wijkander (eds.). Contract Economics. Oxford: Basil Blackwell.

Jensen, M.C. (1983), "Organization theory and methodology," The Accounting Review (April):319-339. 
Jensen, M.C. (1985), "Takeovers - folklore and science," Harvard Business Review 62: 109-121.

Klein, Benjamin, Robert G. Crawford and Armen A. Alchian (1978), "Vertical integration, Appropriable Rents, and the Competitive Contracting Process," Journal of Law and Economics, 21, 297-336.

Kreps, D.M. (1990), "Corporate culture and economic theory," In Alt, J.E. \& K. Shepsle (eds.). Perspectives on Positive Political Economy. Cambridge: Cambridge University Press. pp. 90-143

Larsson, R. \& S. Finkelstein (1999), "Integrating strategic, organizational and human resource perspectives on mergers and acquisitions: a case survey of synergy realization," Organization 4: 187-209.

Malmgren, H.B. (1961), "Information, expectations and the theory of the firm," Quarterly Journal of Economics 75: 391-421.

Manne, H. (1965), "Mergers and the market for corporate control," Journal of Political Economy 73 (April): 11020.

Nelson, R.R. \& S.G. Winter (1982), An Evolutionary Theory of Economic Change.Cambridge: Harvard University Press.

Pablo, A.L. (1994), "Determinants of acquisition integration level," Academy of Management Journal 37: 803-836.

Parvinen, Petri (2003), "Towards a Governance Perspective to Mergers and Acquisitions," Doctoral Dissertation.

Penrose, E.T. (1959), "The Theory of the Growth of the Firm," Oxford: OUP.

Porter, M.E. (1985), Competitive Advantage: Creating and Sustaining Superior Performance, New York: Free Press

Porter, M.E. (1987), "From competitive advantage to corporate strategy," Harvard Business Review 65: 43-59.

Porter, M.E. and M.B. Fuller, (1986), “Coalitions and Global Strategy,”, Porter, M.E. (ed.). Competition in Global Industries. Boston, MA: Harvard Business School Press. Pp. 315-343.

Porter, Michael E. (1980), "Competitive Strategy," New York: NY: the Free Press.

Puranam, P. (2001), "The Management and Performance of Technology Grafting Acquisitions," Management Department, The Wharton School, University of Pennsylvania. Work-In-Progress. 
Ranft, A. (1997), "Preserving and Transferring Knowledge Resources During PostAcquisition Implementation," Doctoral Thesis. Management Department, The Wharton School, University of Pennsylvania.

Richter, A. (1999), Corporate Restructuring in the United Kingdom and West Germany: Recent Developments in Large Non-Financial Companies. London: London School of Economics and Political Science.

Roll, R. (1986), "The hubris hypothesis of corporate takeovers," Journal of Business 59 (2): $197-216$

Ross, S. (1973), "The economic theory of agency: the principal's problem," American Economic Review 63: 134-139

Rumelt, R.P. \& P. Steven. (1992), "Incentives, routines, and self-command," Industrial and Corporate Change 1 (3): 397-425.

Rumelt, R.P. (1974), Strategy, Structure and Economic Performance. Boston: Division of research, Graduate School of Business Administration, Harvard University.

Rumelt, R.P., D.E. Schendel \& D.J. Teece (eds.). (1994), Fundamental Issues in Strategy.Boston: Harvard Business School Press.

Simon, H.A. (1945), Administrative Behavior. New York: Macmillan.

Simon, H.A. (1951), "A formal theory of the employment relationship," Econometrica 19: 293-305

Singh, H. \& C.A. Montgomery. (1987), "Corporate acquisition strategies and economic performance," Strategic Management Journal 8: 377-386.

Stigler, G.J. (1950), "Monopoly and oligopoly by merger," American Economic Review 40: 23-34

Stigler, G.J. (1951), "The economists and the monopoly problem," American Economic Review 72: 1-11.

Teece, D. J., G. Pisano \& A. Shuen (1990) "Firm Capabilities, Resources and the Concept of Strategy. Consortium on Competitiveness and Cooperation," Working Paper 90-9, University of California at Berkeley, Center for Research in Management, Berkeley, CA.

Trautwein, Friedrich (1990), "Mergers Motives and Mergers Prescriptions," Strategic Management Journal, 11 (4), 283-95.

Walsh, J.P. (1988) "Top management turnover following mergers and acquisitions," Strategic Management Journal 9 (2): 173-183. 
Walsh, J.P. (1989), "Doing a deal: merger and acquisition negotiations and their impact upon target company top management turnover," Strategic Management Journal 10 (4): 307-322.

Weston, J.F., J.A. Siu \& B.A. Johnson (2001), Takeovers, Restructuring, and Corporate Governance, 3rd ed. Upper Saddle River, N.J.: Prentice Hall.

Williamson, O.E. (1971), "The vertical integration of production: market failure considerations," American Economic Review 61: 112-123

Williamson, O.E. (1975) Markets and Hierarchies. New York: Free Press.

Williamson, O.E. (1977), "Economics as an antitrust defense revisited," University of Pennsylvania Law Review 125: 699-736.

Williamson, O.E. (1985), The Economic Institutions of Capitalism. New York: Free Press.

Williamson, O.E. (1986), Economic Organization: Firms, Markets and Policy Control. Brighton: Wheatsleaf.

Williamson, O.E. (1991), "Comparative economic organisation: the analysis of discrete structural alternatives," Administrative Science Quarterly 36: 269-296.

Williamson, O.E. 1996. The Mechanisms of Governance. New York: OUP.

Zollo, M. \& H. Singh (2000), "The impact of knowledge codification, experience trajectories and integration strategies on the performance of corporate acquisitions," Working Paper. Management Department, The Wharton School, University of Pennsylvania.

Zollo, M. (1998), "Knowledge Codification, Process Reutilization, and the Creation of Organizational Capabilities: Post-Acquisition Management in the US Banking Industry," Dissertation, UMI. 